Article

\title{
Decomposition of Intermolecular Interactions in the Crystal Structure of Some Diacetyl Platinum(II) Complexes: Combined Hirshfeld, AIM, and NBO Analyses
}

\author{
Saied M. Soliman ${ }^{1,3, *}$ and Assem Barakat ${ }^{2,3}$ \\ 1 Department of Chemistry, Rabigh College of Science and Art, King Abdulaziz University, P.O. Box 344, \\ Rabigh 21911, Saudi Arabia \\ 2 Department of Chemistry, College of Science, King Saud University, P.O. Box 2455, \\ Riyadh 11451, Saudi Arabia; ambarakat@ksu.edu.sa \\ 3 Department of Chemistry, Faculty of Science, Alexandria University, P.O. Box 426, Ibrahimia, \\ Alexandria 21321, Egypt \\ * Correspondence: saied1soliman@yahoo.com; Tel.: +20-111-136-1059; Fax: +20-359-324-88
}

Academic Editor: Derek J. McPhee

Received: 23 October 2016; Accepted: 30 November 2016; Published: 6 December 2016

\begin{abstract}
Intermolecular interactions play a vital role in crystal structures. Therefore, we conducted a topological study, using Hirshfeld surfaces and atom in molecules (AIM) analysis, to decompose and analyze, respectively, the different intermolecular interactions in six hydrazone-diacetyl platinum(II) complexes. Using AIM and natural bond orbital (NBO) analyses, we determined the type, nature, and strength of the interactions. All the studied complexes contain $\mathrm{C}-\mathrm{H} \cdots \mathrm{O}$ interactions, and the presence of bond critical points along the intermolecular paths underlines their significance. The electron densities $(\rho(\mathrm{r}))$ at the bond critical points $\left(0.0031-0.0156 \mathrm{e} / \mathrm{a}_{0}{ }^{3}\right)$ fall within the typical range for H-bonding interactions. Also, the positive values of the Laplacian of the electron density $\left(\nabla^{2} \rho(\mathrm{r})\right)$ revealed the depletion of electronic charge on the interatomic path, another characteristic feature of closed-shell interactions. The ratios of the absolute potential energy density to the kinetic energy density $(|V(\mathrm{r})| / G(\mathrm{r}))$ and $\rho(\mathrm{r})$ are highest for the $\mathrm{O} 2 \cdots \mathrm{H} 15-\mathrm{N} 3$ interaction in $\left[\mathrm{Pt}(\mathrm{COMe})_{2}\left(2-\mathrm{pyCMe}=\mathrm{NNH}_{2}\right)\right](1)$; hence, this interaction has the highest covalent character of all the $\mathrm{O} \cdots \mathrm{H}$ intermolecular interactions. Interestingly, in $\left[\mathrm{Pt}(\mathrm{COMe})_{2}\left(\mathrm{H}_{2} \mathrm{NN}=\mathrm{CMe}-\mathrm{CMe}=\mathrm{NNH}_{2}\right)\right]$ (3), there are significant $\mathrm{N}-\mathrm{H} \cdots \mathrm{Pt}$ interactions. Using the $\mathrm{NBO}$ method, the second-order interaction energies, $E^{(2)}$, of these interactions range from 3.894 to $4.061 \mathrm{~kJ} / \mathrm{mol}$. Furthermore, the hybrid $\mathrm{Pt}$ orbitals involved in these interactions are comprised of $\mathrm{d}_{\mathrm{xy}}, \mathrm{d}_{\mathrm{xz}}$, and $\mathrm{s}$ atomic orbitals.
\end{abstract}

Keywords: diacetyl platinum(II); topology; Hirshfeld; AIM; NBO

\section{Introduction}

In a crystal, the molecules are packed in a unique pattern held together by weak and strong intermolecular interactions. These interactions strongly affect each other [1] where small changes in the molecular structure produce significant changes in the crystal structure. In general, there is no clear relationship between the molecular structure and the crystal structure. One of the most common intermolecular interactions is with hydrogen bonds, which play an important role in crystal engineering, and hence, the role of hydrogen bonding in a variety of molecules and crystals has been investigated [1].

The theory of atoms in molecules (AIM) proposed by Bader offers a simple method to understand the various intermolecular interactions in molecular systems [2]. The AIM theory yields 
significant information about the changes in electron distribution due to bond and complex formation. The concepts of chemical bonding and bond strength can be explained using the electron density distribution functions [2,3], obtained from the AIM theory. In this topological analysis, the electron density description of chemical bonding is made using bond paths and bond critical points (BCP). The BCP is a point between two interacting atoms where the gradient of the electron density is zero, indicating a significant interaction between these atoms. For hydrogen bonds, the presence of a BCP on the hydrogen bond path indicates the presence of a hydrogen bond. In addition, topological descriptors such as the electron density $(\rho(\mathrm{r}))$ and the Laplacian of the electron density $\left(\nabla^{2} \rho(\mathrm{r})\right)$ at the BCP can be obtained from the AIM theory. These descriptors and others have been used to characterize the strength of hydrogen bonds in various molecular systems. Furthermore, these descriptors can be employed to distinguish between covalent and ionic bonding, hydrogen bonding, and van der Waals $(\mathrm{vdW})$ interactions [4]. In addition, natural bond orbital (NBO) analysis gives another route for the study of intermolecular interactions within molecular systems.

Platinum(II) complexes have great importance in the field of cancer chemotherapy [5-7]. For example, cisplatin and carboplatin are the most common Pt-based drugs used for cancer treatment. These medications have almost $100 \%$ cure rate for the treatment of ovarian, testicular, and bladder cancers [6,7]. Because of the importance of Pt compounds in cancer therapy, many Pt-based anticancer drugs have been synthesized and have entered clinical use [8-13]. In this study, the significant intermolecular contacts obtained from Hirshfeld analyses of the solid-state crystal structures of six structurally related hydrazone-diacetyl platinum(II) complexes were investigated, and AIM and NBO analyses were used to understand the type, nature, and strength of these interactions. We placed particular focus on the characterization of hydrogen-bonding interactions.

\section{Results and Discussion}

\subsection{Hirshfeld Analysis}

Molecular Hirshfeld surfaces of molecules in a crystal structure are constructed based on the electron distribution, which is calculated as the sum of spherical atom electron densities [14-22]. The Hirshfeld (HF) surface is unique [23-26] for each crystal. The properties of the surface yield information about the intermolecular interactions in the crystal. Each point on the Hirshfeld surface represents two distances: (1) the distance from this point to the nearest external nucleus $\left(d_{\mathrm{e}}\right)$ and (2) the distance to the nearest internal nucleus $\left(d_{\mathrm{i}}\right)$. Graphical plots of the molecular Hirshfeld surfaces are mapped with the normalized contact distance $\left(d_{\text {norm }}\right)$, and these indicate regions of important intermolecular interactions [14-22,27,28]. The value of the $d_{\text {norm }}$ is represented by red, white, or blue when the intermolecular contacts are shorter, equal, or longer to the vdW separation, respectively. The combination of $d_{\mathrm{e}}$ and $d_{\mathrm{i}}$ in the form of a 2D fingerprint plot gives a summary of the intermolecular contacts in the crystal $[14,23,26,29]$. The fingerprint plots can be decomposed to highlight particular atom pair close contacts $[23,28]$ (Figure S1). This decomposition enables separation of contributions from different interaction types, which overlap in the full fingerprint. Also, it provides a valuable quantitative analysis of the intermolecular interactions occurring in the crystal structure.

The atom numbering schemes according to the X-ray structures of the studied Pt-complexes are shown in Figure 1. The front and back views of the Hirshfeld surfaces together with the fingerprint plots of the six Pt complexes are shown in Figure 2. The decomposed fingerprint maps for all possible interactions are given in the Supplementary Data (Figure S1). The most significant intermolecular interactions in the crystal lattice of the studied complexes are listed in Table 1 and shown in Figures 3-8. In the same table, the minimum contact distances between two interacting atoms are given in brackets. 


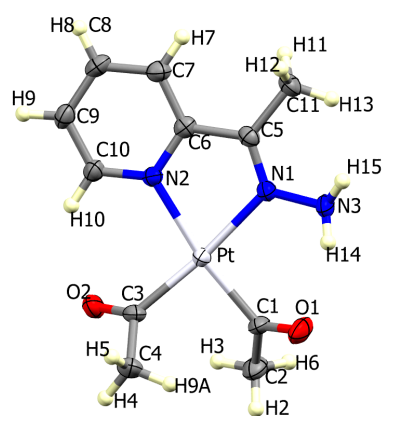

1

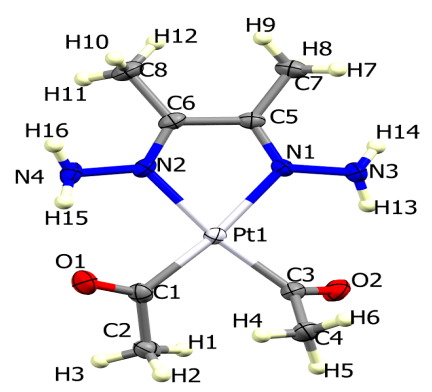

3

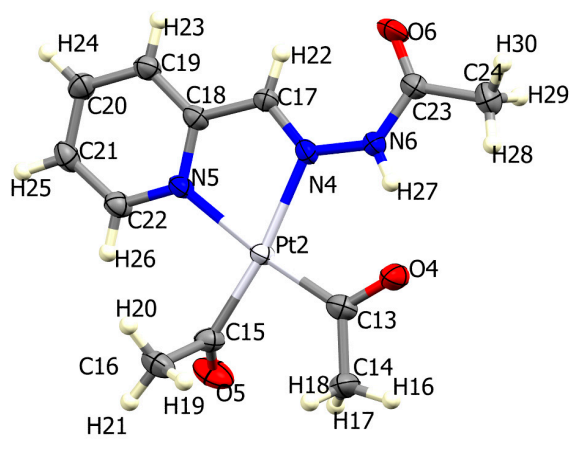

5 (unit 2)

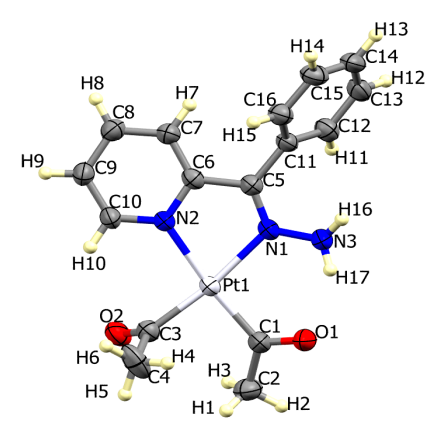

2 (unit 1)

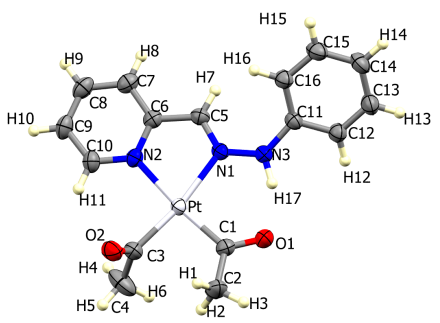

4

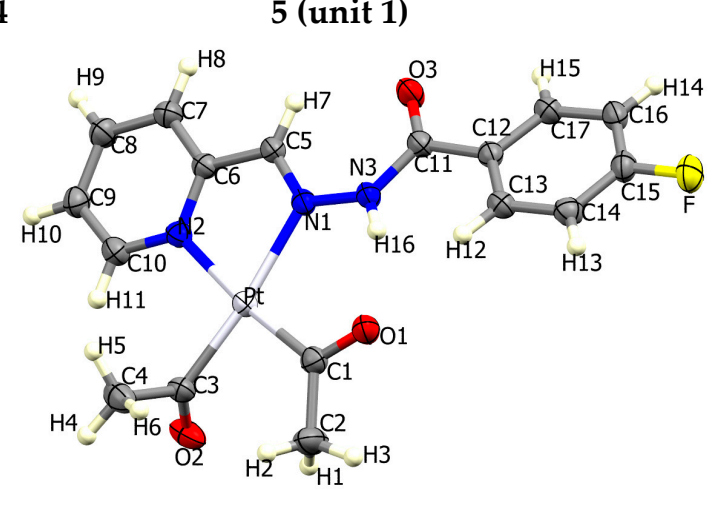

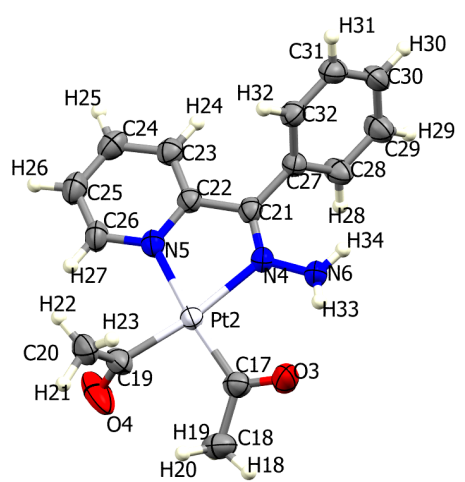

2 (unit 2)

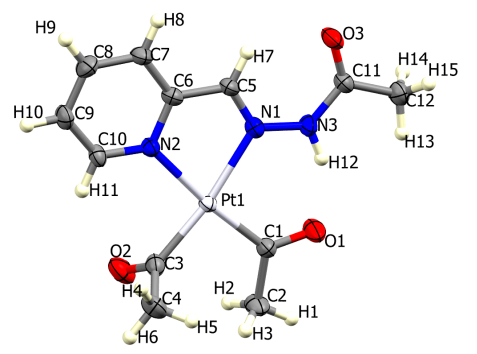

Figure 1. Atomic numbering in the six Pt complexes (front view).

Front

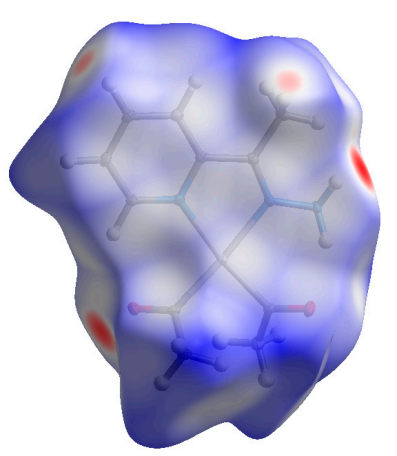

Back

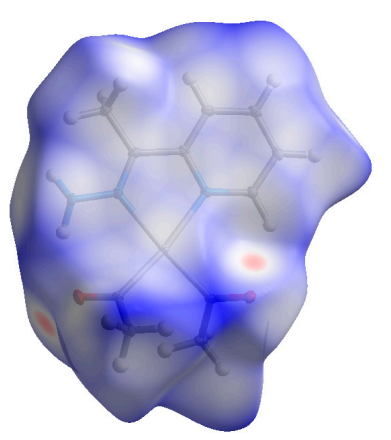

Complex $1\left(d_{\text {norm }}=-0.402\right.$ to 1.450$)$

6

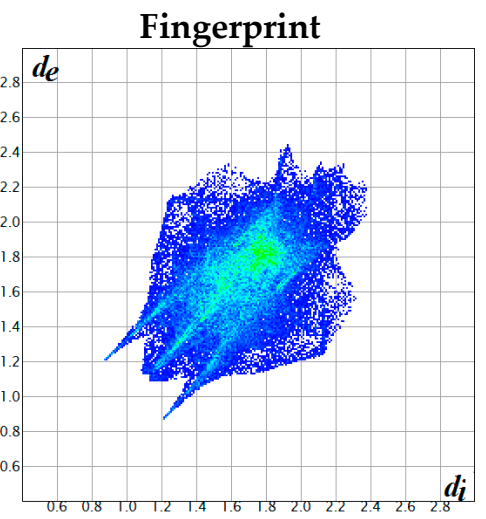

Figure 2. Cont. 

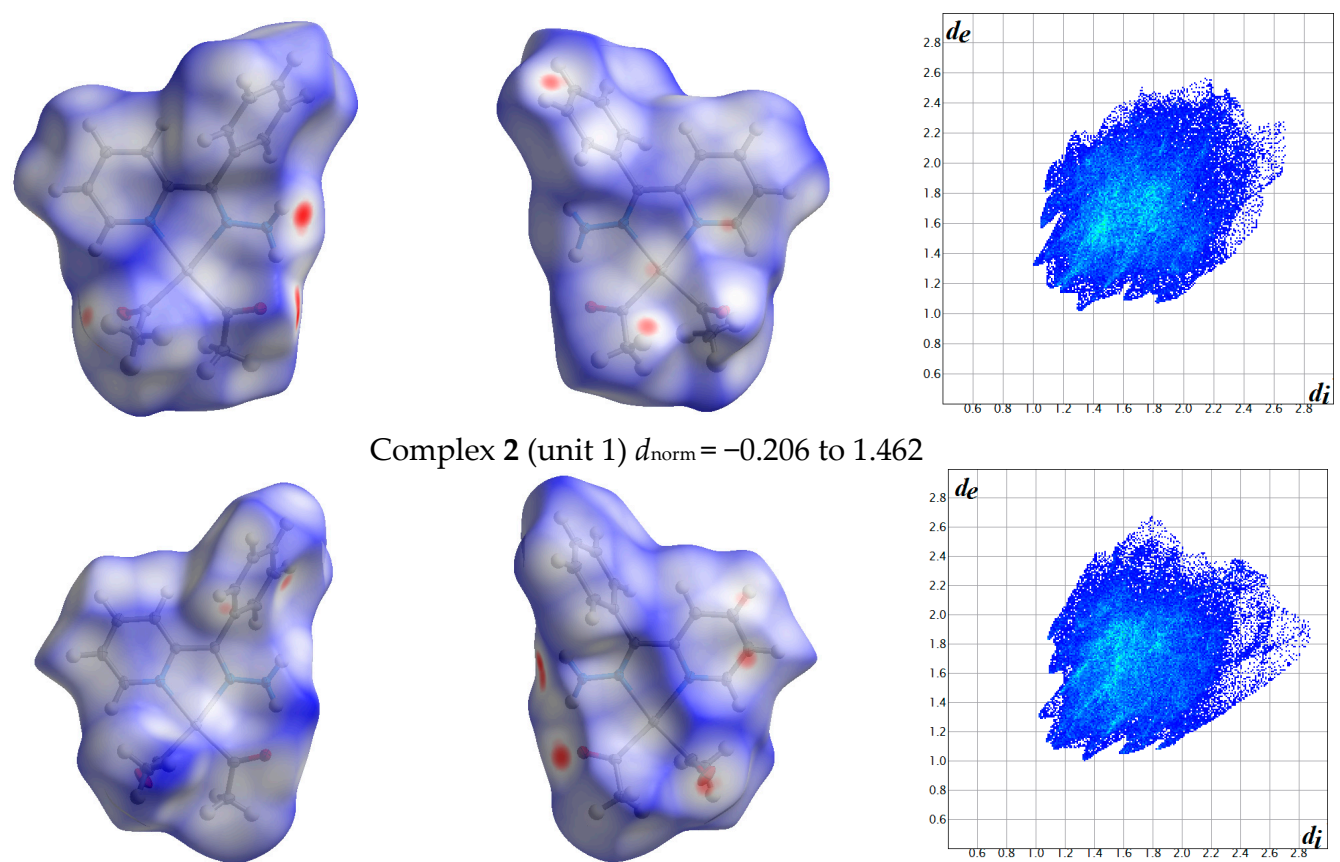

Complex 2 (unit 1) $d_{\text {norm }}=-0.206$ to 1.462
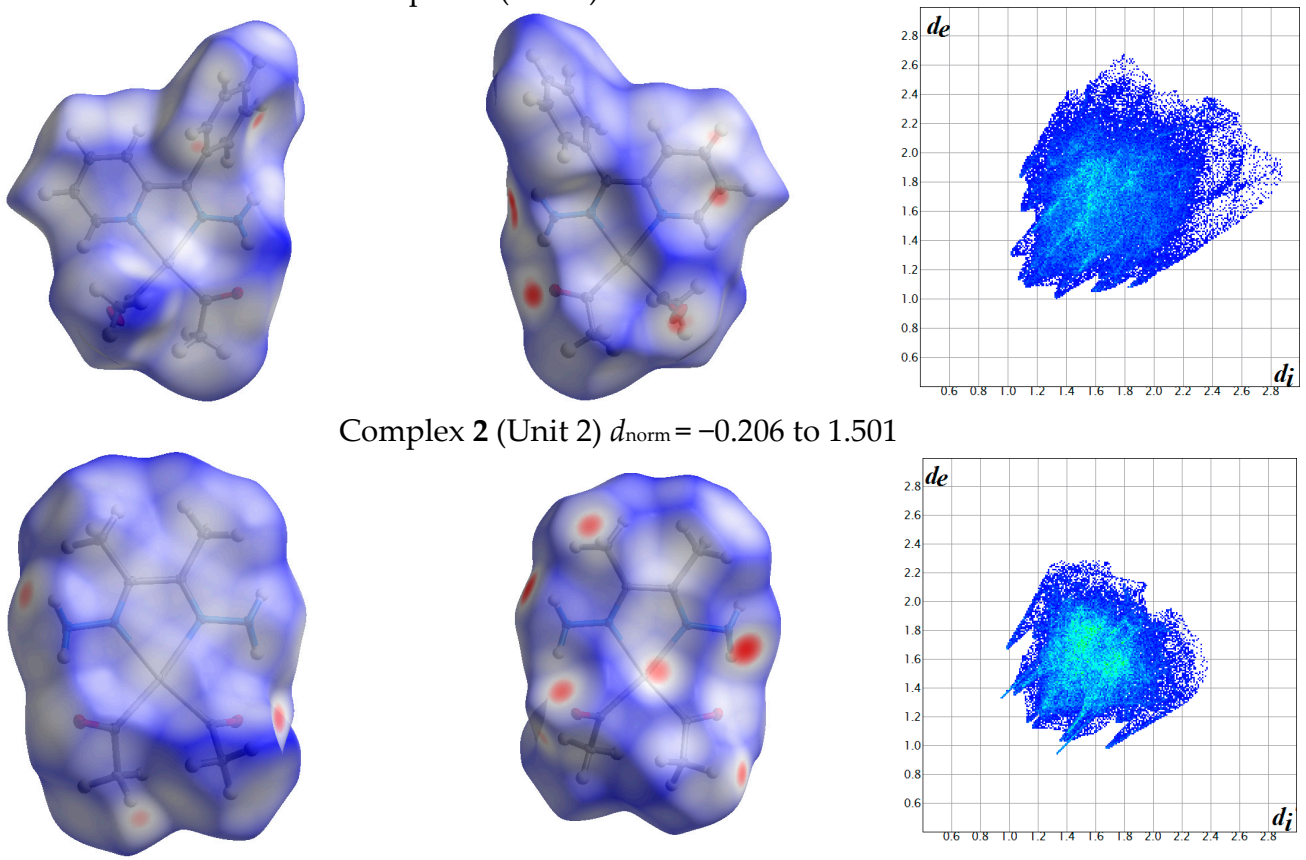

Complex 2 (Unit 2) $d_{\text {norm }}=-0.206$ to 1.501
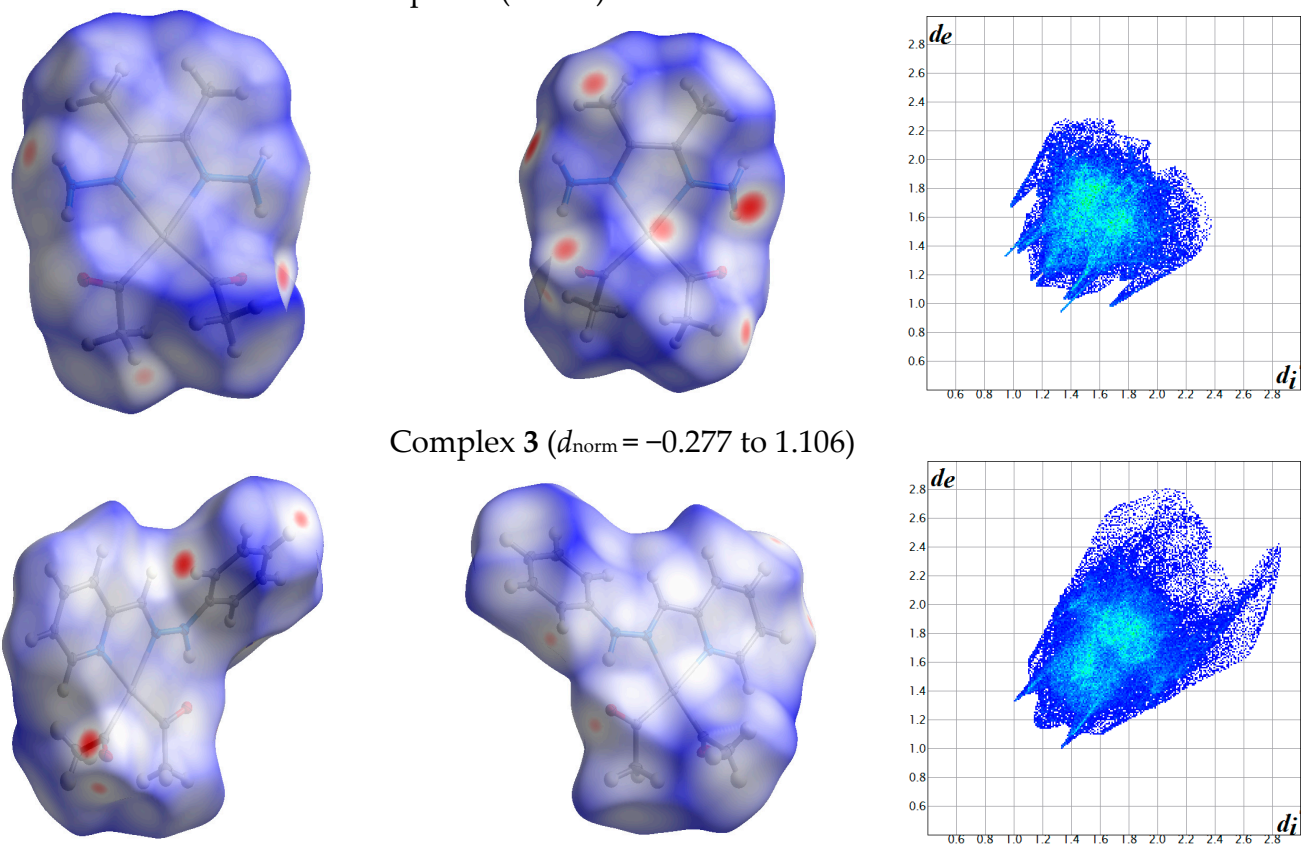

Complex $3\left(d_{\text {norm }}=-0.277\right.$ to 1.106$)$
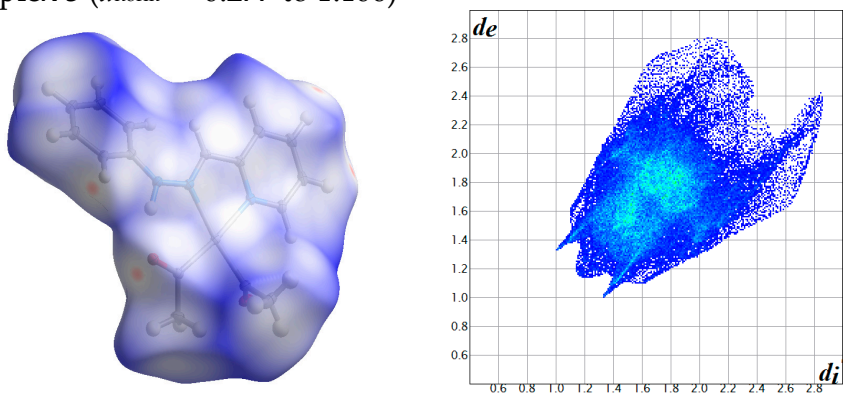

Complex $4\left(d_{\text {norm }}=-0.201\right.$ to 1.677$)$
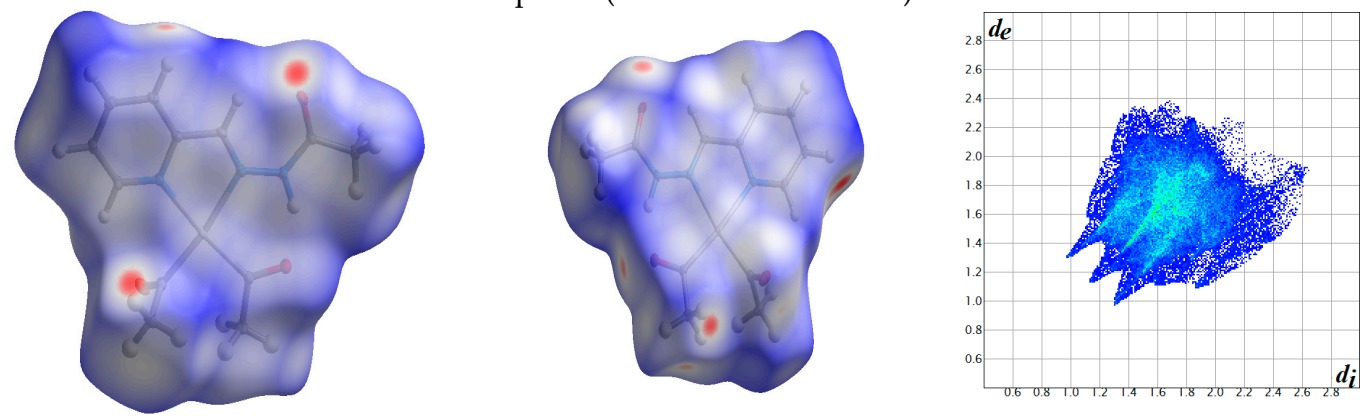

Figure 2. Cont. 
Complex 5 (unit 1) $d_{\text {norm }}=(-0.247$ to 1.417$)$
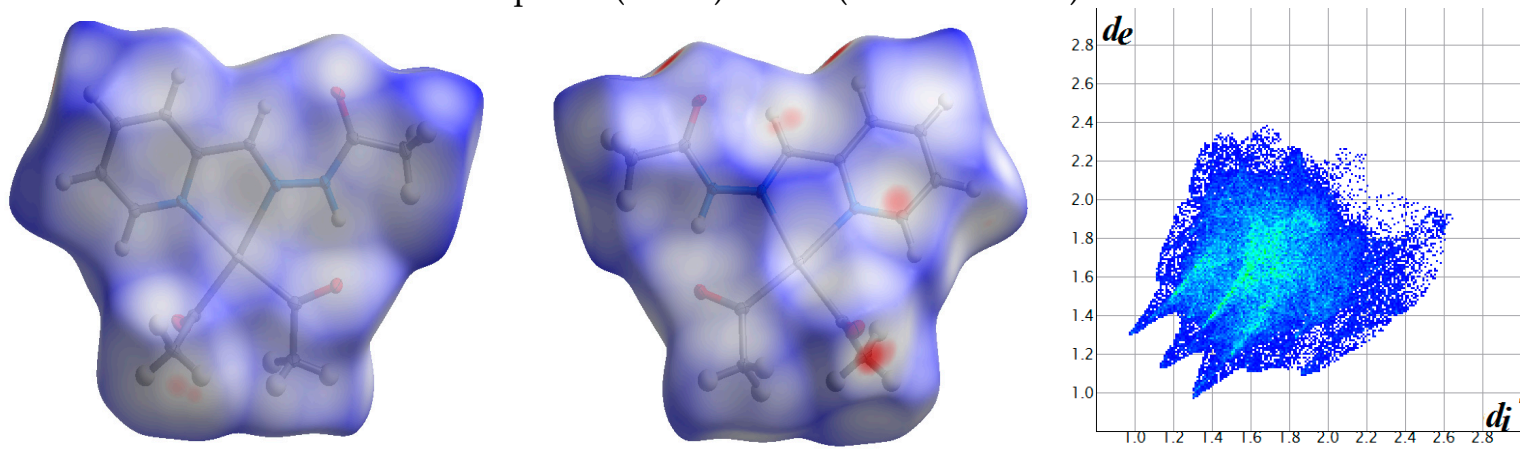

Complex 5 (unit 2) $d_{\text {norm }}=(-0.247$ to 1.417$)$
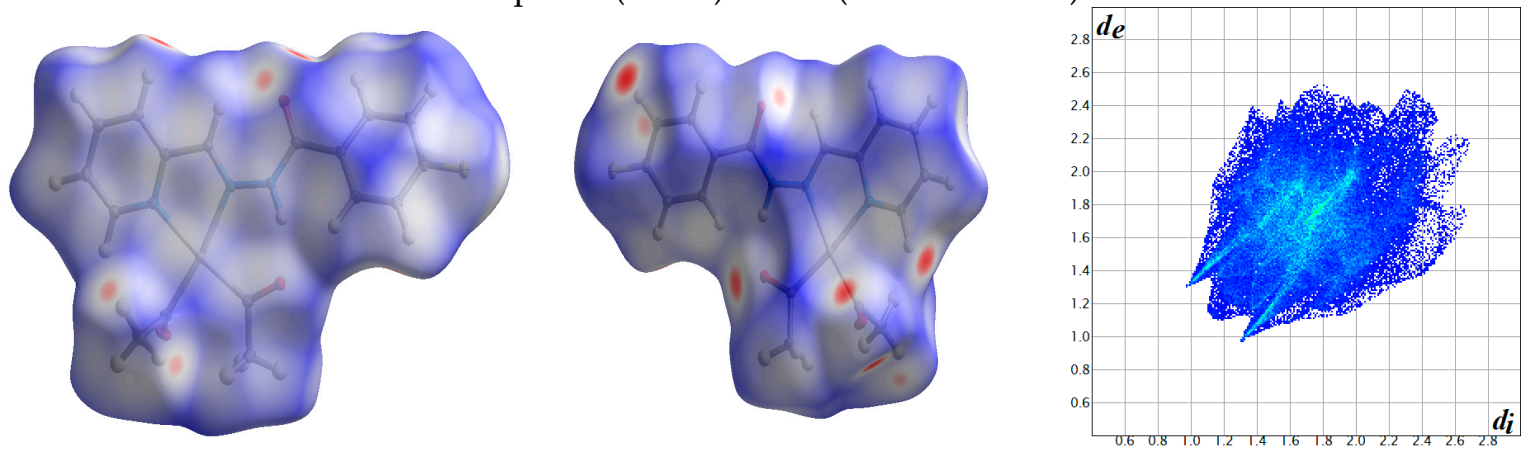

Complex $6\left(d_{\text {norm }}=-0.248\right.$ to 1.315$)$

Figure 2. Hirshfeld surfaces and full fingerprint plots of the studied complexes; front views are referred to Figure 1.

Many common intermolecular interactions, such as $\mathrm{H} \cdots \mathrm{H}, \mathrm{H} \cdots \mathrm{C}$, and $\mathrm{H} \cdots \mathrm{O}$ contacts, play a crucial role in the crystal packing of these Pt complexes. The $\mathrm{H} \cdots \mathrm{H}$ intermolecular contacts make the largest contribution (34.9\%-57.0\%) in the fingerprint maps of all complexes, and it is believed that these intermolecular interactions play a major role in crystal lattice stability [30]. The minimum $\mathrm{H} \cdots \mathrm{H}$ contact distances are 2.230, 2.206, 2.288, 2.320, 2.017, and $2.250 \AA$ for complexes 1-6, respectively. In all complexes, the contact distances are more than twice the van der Waals radius of a hydrogen atom, except for those of complex 5, where the minimum $\mathrm{H} \cdots \mathrm{H}$ intermolecular separation is slightly less than twice the van der Waals radius of a hydrogen atom.

Table 1. Summary of the most important intermolecular contacts and their percentage contributions in the crystal structure of the studied complexes. The minimum contact distances are in angstroms.

\begin{tabular}{ccccccccc}
\hline Contact & $\mathbf{1}$ & $\mathbf{2 ~ ( 1 )}$ & $\mathbf{2 ~ ( 2 )}$ & $\mathbf{3}$ & $\mathbf{4}$ & $\mathbf{5 ( 1 )}$ & $\mathbf{5 ( 2 )}$ & $\mathbf{6}$ \\
\hline $\mathrm{C} \cdots \mathrm{H} \%$ & $5.0(2.878)$ & $16.2(2.632)$ & $18.2(2.632)$ & $3.5(2.876)$ & $18.3(2.703)$ & $11.8(2.699)$ & $7.5(2.675)$ & $19.3(2.669)$ \\
$\mathrm{C} \cdots \mathrm{N} \%$ & $8.6(3.392)$ & $1.2(3.369)$ & $1.1(3.369)$ & $2.3(3.381)$ & $4.6(3.383)$ & $3.1(3.318)$ & $5.2(3.487)$ & $3.9(3.388)$ \\
$\mathrm{C} \cdots \mathrm{C} \%$ & $1.6(3.509)$ & $2.1(3.523)$ & $1.8(3.523)$ & $0.2(3.646)$ & $1.1(3.427)$ & $1.2(3.315)$ & $2.4(3.446)$ & $3.3(3.375)$ \\
$\mathrm{C} \cdots \mathrm{PT} \%$ & $2.2(3.474)$ & $0.2(3.356)$ & $0.2(3.356)$ & $0.3(3.629)$ & $2.8(3.430)$ & 0.0 & $2.6(3.682)$ & $0.9(3.484)$ \\
$\mathrm{H} \cdots \mathrm{H} \%$ & $57.0(2.230)$ & $51.7(2.206)$ & $52.4(2.206)$ & $54.1(2.288)$ & $53.8(2.320)$ & $46.8(2.017)$ & $48(2.017)$ & $34.9(2.250)$ \\
$\mathrm{H} \cdots \mathrm{O} \%$ & $19.0(2.083)$ & $18.0(2.323)$ & $14.5(2.323)$ & $21.2(2.385)$ & $14.6(2.338)$ & $27.3(2.324)$ & $24.3(2.324)$ & $19.8(2.278)$ \\
$\mathrm{H} \cdots \mathrm{N} \%$ & $3.5(2.773)$ & $6.8(2.643)$ & $7.7(2.643)$ & $12.1(2.273)$ & $0.4(3.448)$ & $4.1(2.908)$ & $2.2(3.510)$ & $1.5(3.328)$ \\
$\mathrm{H} \cdots \mathrm{Pt} \%$ & $2.7(3.361)$ & $3.1(2.901)$ & $3.4(2.901)$ & $5.3(2.650)$ & $0.9(3.329)$ & $3.0(2.960)$ & $2.2(2.960)$ & $2.4(3.057)$ \\
$\mathrm{F} \cdots \mathrm{H} \%$ & & & & & & & & $9.5(2.544)$ \\
\hline
\end{tabular}

O $\cdots$ H intermolecular interactions are another type of close contact that makes a large contribution to the crystal lattice of all the studied complexes. These structures having shorter intermolecular $\mathrm{O} \cdots \mathrm{H}$ contact distances than the sum of the van der Waals radii are shown in Figures 3-8. The O $\cdots \mathrm{H} \%$ is highest for complexes 3 and 5. Three types of $\mathrm{H} \cdots \mathrm{O}$ interactions were detected. The N-H. O 
interactions have the shortest hydrogen bond distances. The $\mathrm{O} \cdots \mathrm{H}$ distances for these interactions are $2.083 \AA$ and 2.323-2.332 Å for complexes 1 and 2, respectively. The other complexes did not show this type of interaction. Moreover, the other two types of $\mathrm{C}-\mathrm{H} \cdots \mathrm{O}$ interactions occurred between either the aliphatic or aromatic $\mathrm{C}-\mathrm{H}$ bonds with the $\mathrm{O}$-atoms of the carbonyl groups of the neighboring molecules. The $\mathrm{H} \cdots \mathrm{C}$ intermolecular contacts also showed high contributions to the overall fingerprint plot, except for complex 3. H. C $\%$ is highest in 2,4 , and 6 , which contain two phenyl rings, while it is lowest in 3, which has no aromatic ring system. The most significant $\mathrm{C} \cdots \mathrm{H}$ intermolecular contact distances are shown in Figures 3-8. These figures showed that the shortest C $\cdots H$ intermolecular distances occurred in 2 . The minimum contact distance in $\mathbf{2}$ is found to be $2.632 \AA$, which is less than the van der Waals radii sum of the two elements. It is well known that the shorter the contact distance compared to the van der Waals radii sum, the more significant the intermolecular interaction.

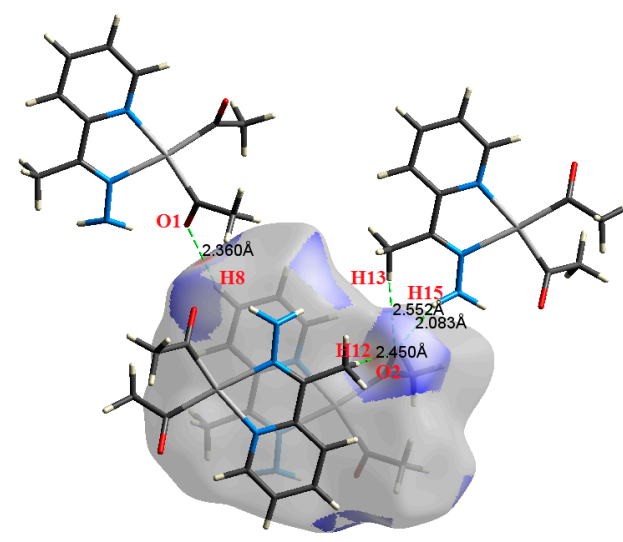

95819

Figure 3. The most important intermolecular contacts in complex $\mathbf{1}$.
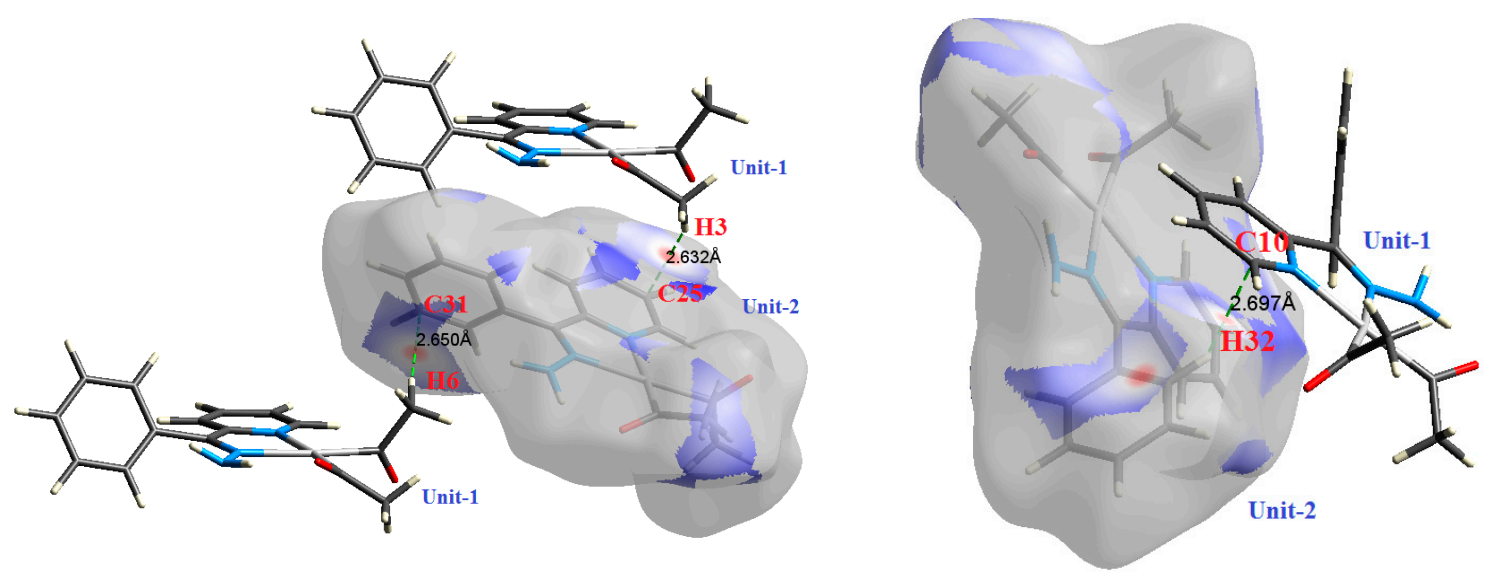

Figure 4. Cont. 

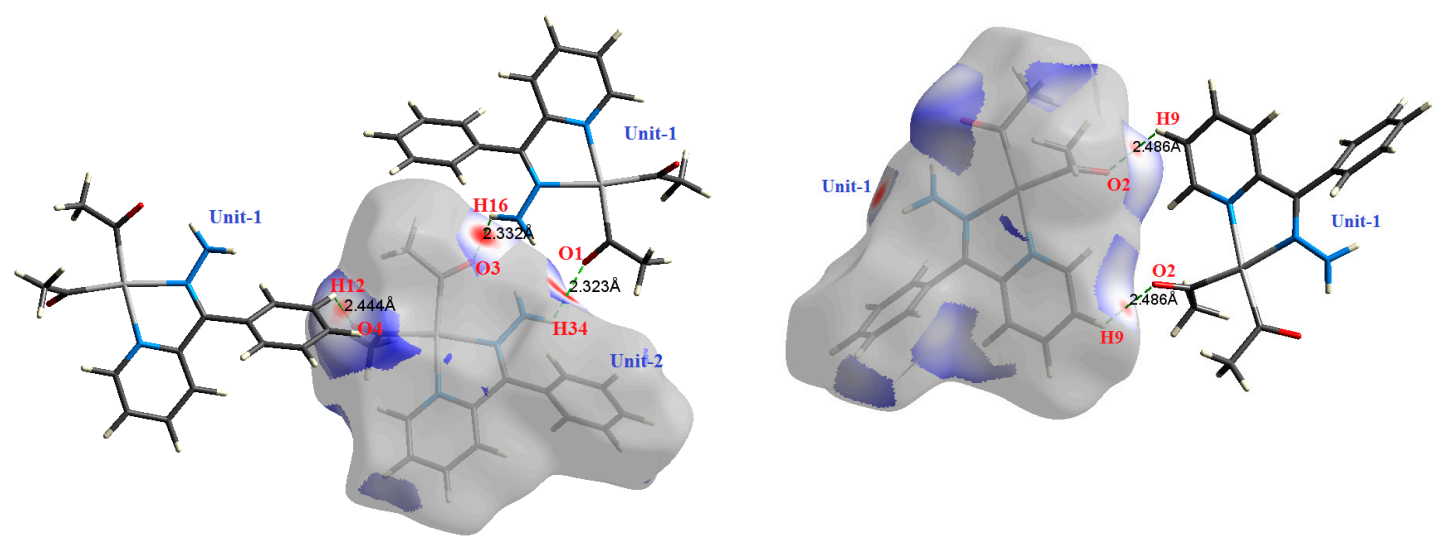

Figure 4. The most important intermolecular contacts in complex 2.
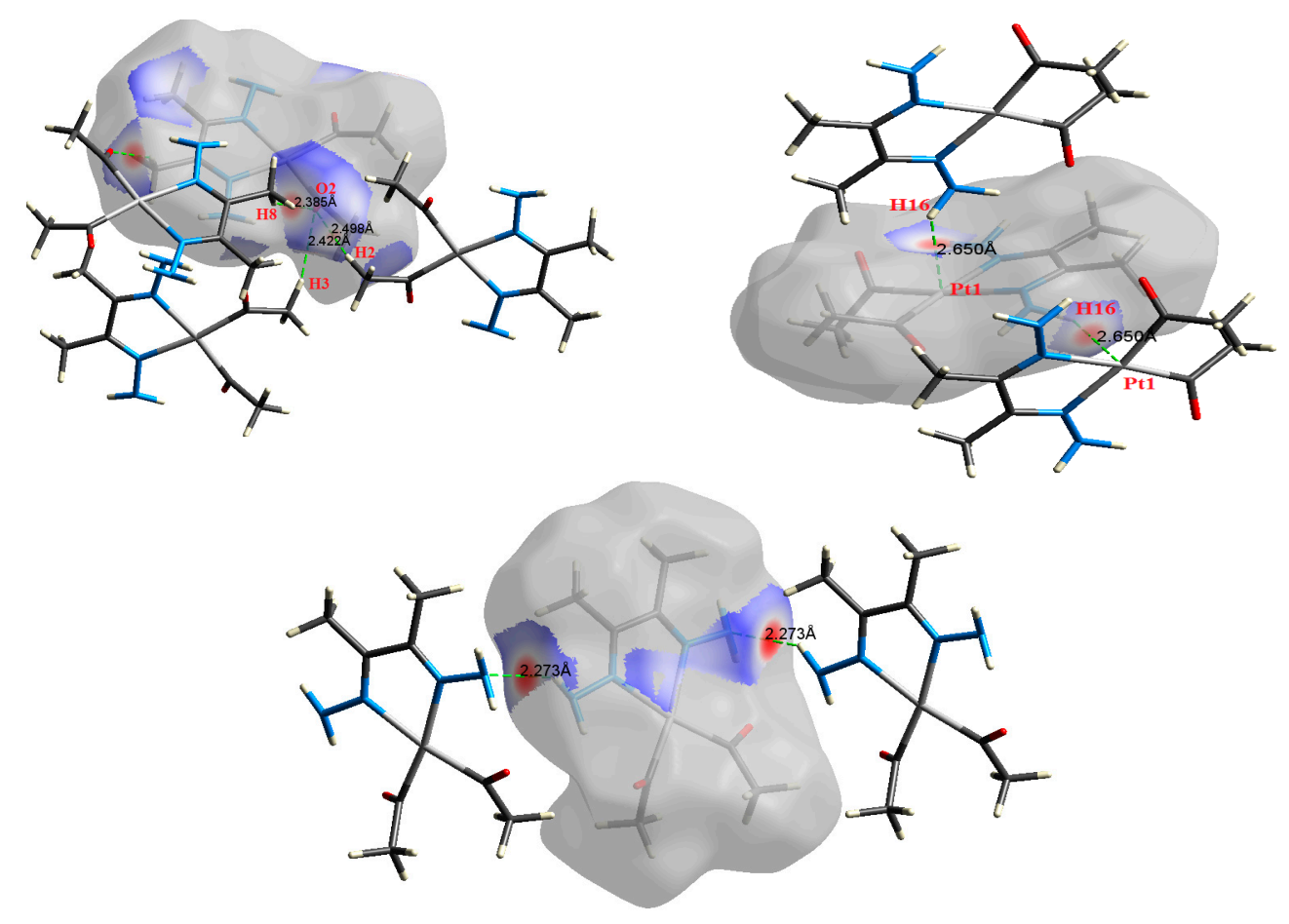

Figure 5. The most important intermolecular contacts in complex 3.
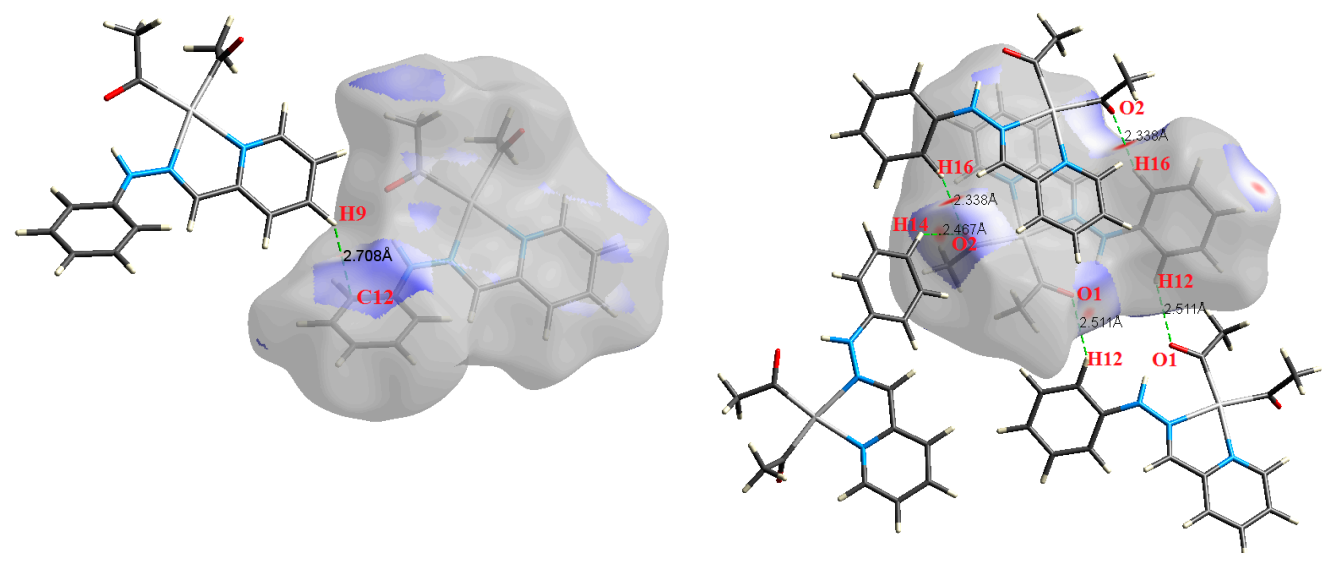

Figure 6. Cont. 


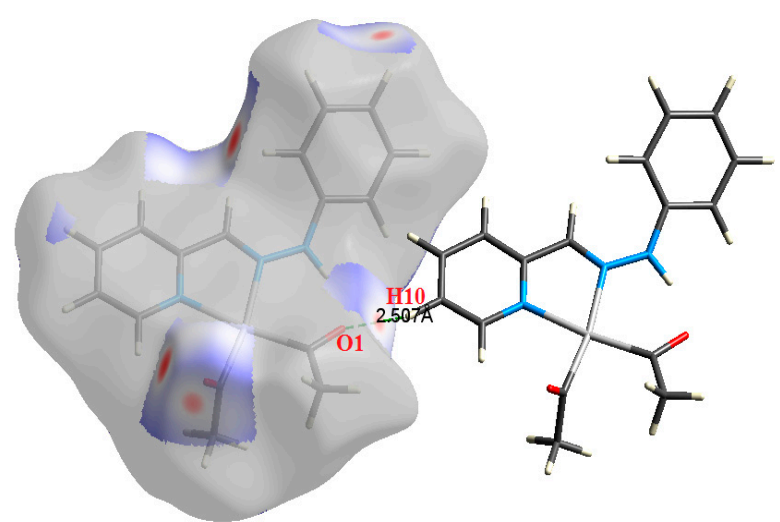

Figure 6. The most important intermolecular contacts in complex 4.
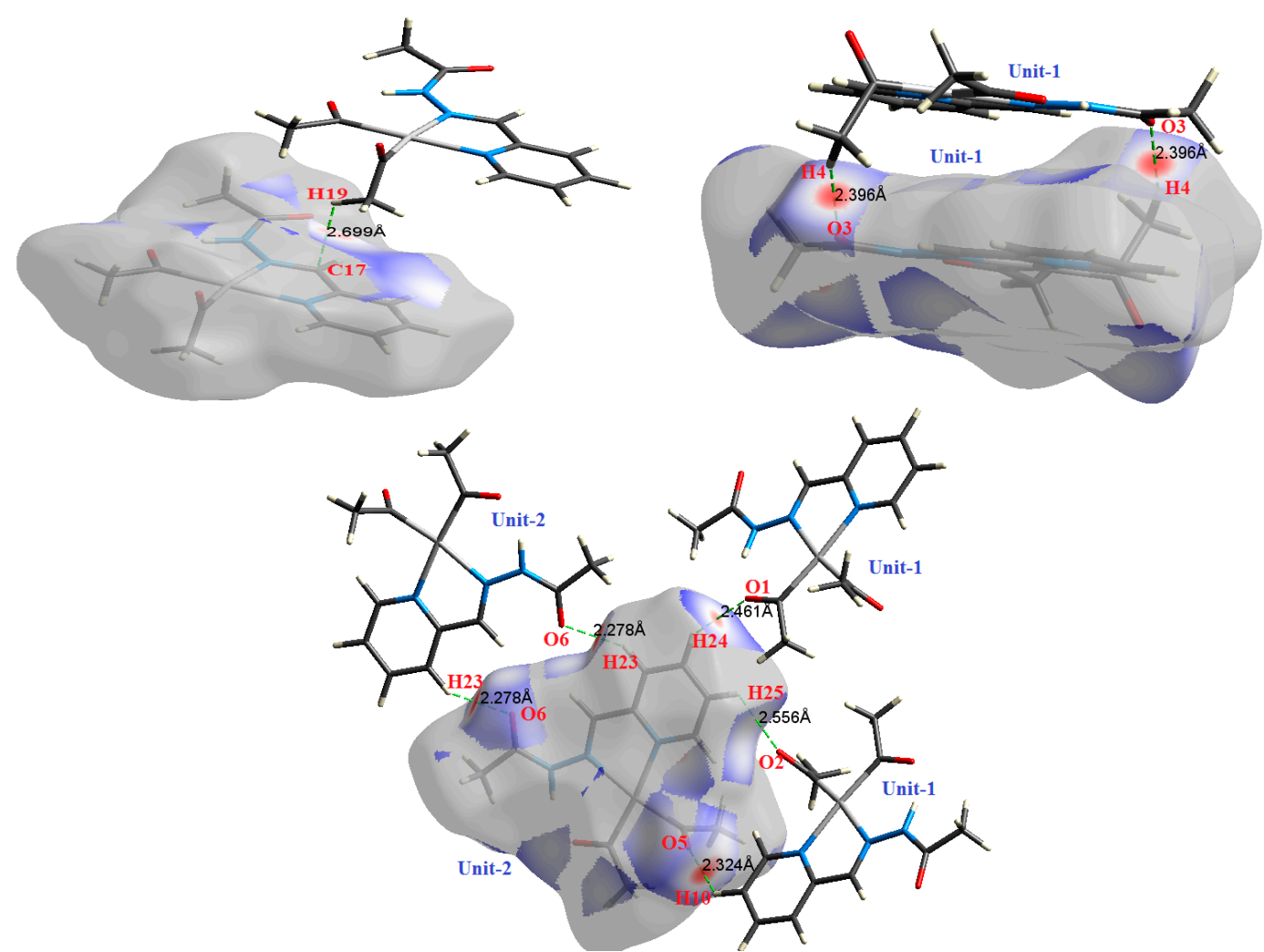

Figure 7. The most important intermolecular contacts in complex 5.
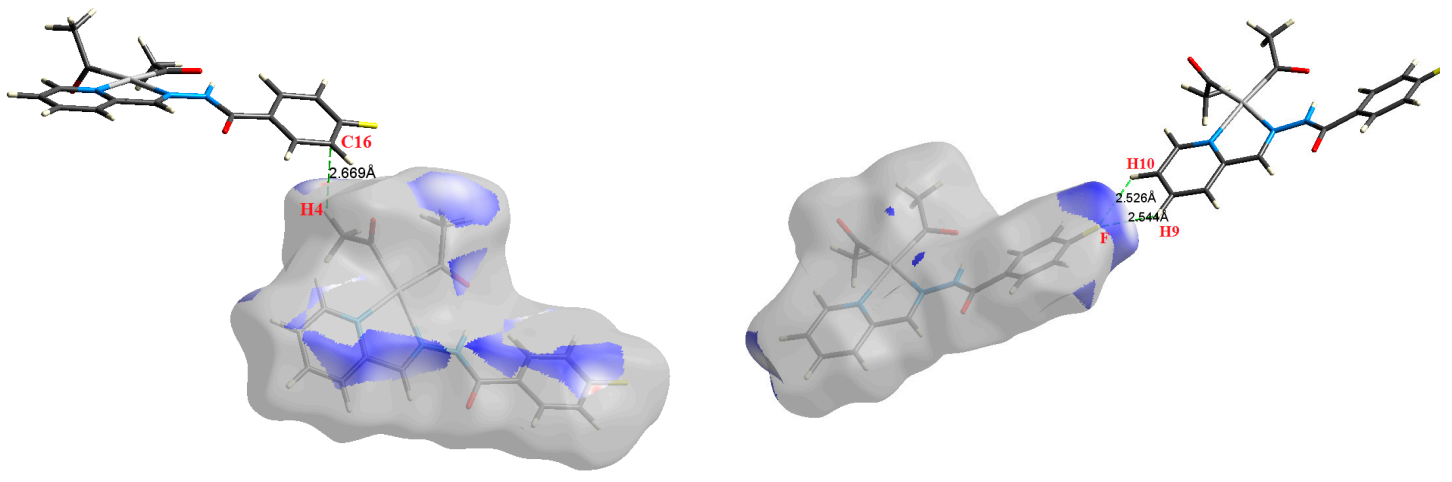

Figure 8. Cont. 


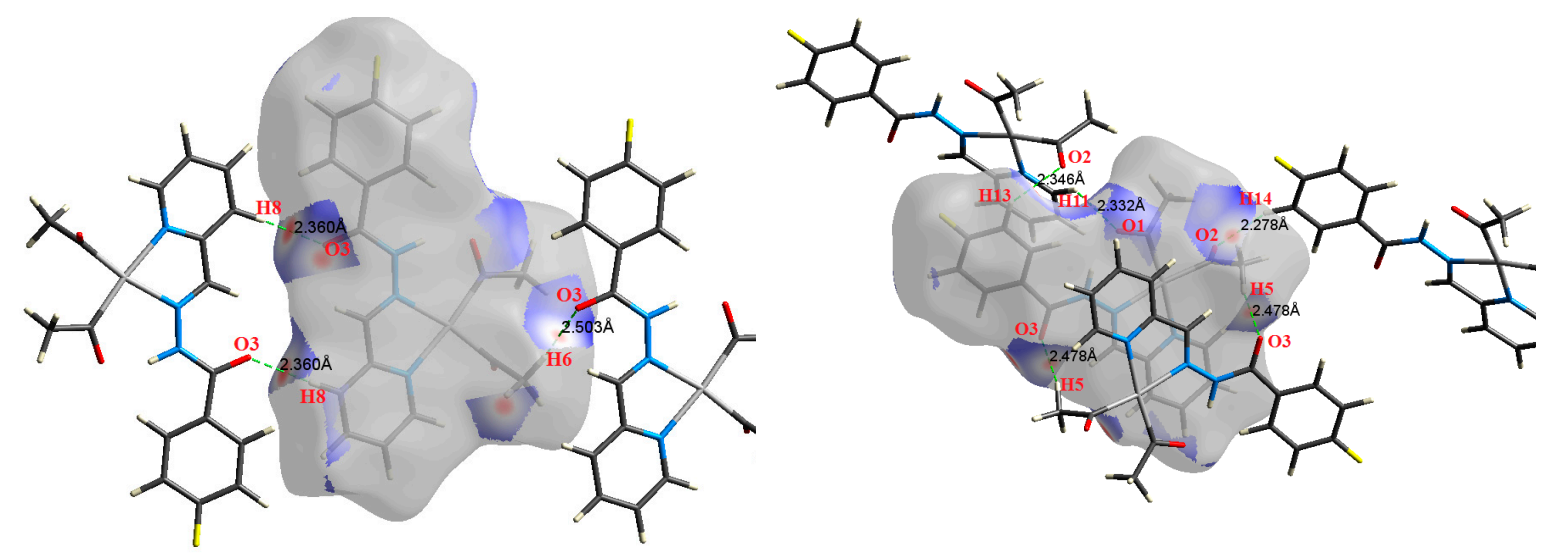

Figure 8. The most important intermolecular contacts in complex 6.

The Hirshfeld surface analysis of complexes 2 and 3 showed the presence of Pt. $\mathrm{H}$ interactions. In 2, the Pt atom from one complex interacts with the H31 of the phenyl ring of neighboring complex; the interactions are very weak, as indicated by the longer contact distance $(2.901 \AA$, which is longer than the $\mathrm{vdW}$ radii sum). In contrast, for 3 , the Pt atom interacts with the N-H proton from a neighboring complex $(2.81 \AA)$. The Pt...H distance, in this case, is $2.650 \AA$, which is less than the sum of the vdW radii. Moreover, complexes 3 and 6 contain $\mathrm{N} \cdots H(2.273 \AA)$ and $\mathrm{F} \cdots \mathrm{H}$ (2.526-2.544 $\AA$ ) intermolecular interactions, respectively, and these contact distances are shorter than the van der Waals radii sum of the two elements. However, the latter range of values is very close to the vdW sum of the two elements ( $\mathrm{F}$ and $\mathrm{H}$ ) and could be considered a weak interaction. Notably, the absence of any significant intermolecular $\mathrm{Pt} \cdots \mathrm{Pt}, \mathrm{Pt} \cdots \mathrm{O}, \mathrm{Pt} \cdots \mathrm{N}$, and Pt $\cdots \mathrm{C}$ contacts indicates the monomeric nature of these complexes. Another significant feature of the Hirshfeld surface analysis is the sensitivity of the fingerprint plots to small variations in geometric parameters. Although the asymmetric units of complexes $\mathbf{2}$ and $\mathbf{5}$ are very similar, their Hirshfeld surfaces and fingerprint plots are unique. The importance of shape index and curvedness plots is explained in the Supplementary Data (Figure S2).

\subsection{AIM Study}

The quantum theory of atoms in molecules [2] is a popular tool for describing various inter- and intra-molecular interactions. The AIM theory uses topological parameters such as the electron density $(\rho(\mathrm{r}))$, the Laplacian of the electron density $\left(\nabla^{2} \rho(\mathrm{r})\right)$, the kinetic energy density $G(\mathrm{r})$, the potential energy density $V(\mathrm{r})$, and the total electron energy density $(H(\mathrm{r})=V(\mathrm{r})+G(\mathrm{r}))$ at the bond critical point $(\mathrm{BCP})$ of interacting atoms or fragments [31-33]. According to Espinosa [34], the interaction energy $\left(E_{\text {int }}\right)$ can be estimated using the potential energy density at the BCP as $E_{\mathrm{int}}=1 / 2(V(\mathrm{r}))$. The topological parameters, as well as the calculated interaction energies $\left(E_{\mathrm{int}}\right)$ of the different intermolecular interactions observed from the Hirshfeld analysis, are listed in Table 2.

Bader's theory showed that the topological properties $\rho(\mathrm{r})$ and $\nabla^{2} \rho(\mathrm{r})$ at the BCP of two hydrogen-bonded atoms are important parameters for investigating these intermolecular interactions. The atomic interactions belong to two general classes: (1) shared interactions, such as covalent and polarized bonds, in which the electronic charge is concentrated on the line of interaction linking the nuclei. For these interactions, $\nabla^{2} \rho(\mathrm{r})<0$ and $\rho(\mathrm{r})$ should be $>10^{-1}$ a.u. (2) Closed-shell interactions, such as hydrogen bonds and van der Waals interactions, in which the electronic charge is concentrated towards each of the interacting nuclei, deplete the electronic charge at the interatomic surface, and in this case, $\rho(r) \approx 10^{-2}$ and $\nabla^{2} \rho(r)>0$. Furthermore, the electron density, $\rho(r)$, has been used to measure the degree of covalency of the intermolecular interactions [4]. Consequently, $\rho(r)$ and $\nabla^{2} \rho(r)$ at the BCP of hydrogen-bonded atoms should be $0.002 \pm 0.035 \mathrm{e} / \mathrm{a}_{0}{ }^{3}$ and $0.024 \pm 0.139 \mathrm{e} / \mathrm{a}_{0}{ }^{5}$, respectively, if a hydrogen bond exists [33]. 
Table 2. Topological parameters obtained from the atom in molecules (AIM) analyses of the most important contacts observed from the Hirshfeld analyses of the Pt complexes.

\begin{tabular}{|c|c|c|c|c|c|c|c|c|}
\hline Contact Type & $D(\AA)$ & $\begin{array}{c}\mathrm{E}_{\mathrm{int}} \\
\text { (kcal/mol) }\end{array}$ & $\begin{array}{c}\rho(\mathbf{r}) \\
\left(\mathrm{e} / \mathrm{a}_{0}{ }^{3}\right)\end{array}$ & $\begin{array}{l}\nabla^{2} \rho(\mathrm{r}) \\
\left(\mathrm{e} / \mathrm{a}_{0}{ }^{5}\right)\end{array}$ & $\begin{array}{c}V(r) \\
\text { (a.u.) }\end{array}$ & $\begin{array}{c}G(r) \\
\text { (a.u.) }\end{array}$ & $\begin{array}{c}H(\mathrm{r}) \\
\text { (a.u.) }\end{array}$ & $|V(\mathbf{r})| / G(\mathbf{r})$ \\
\hline \multicolumn{9}{|c|}{ Complex 1} \\
\hline $\mathrm{C} 9 \cdots \mathrm{N} 3$ & 3.404 & 0.9230 & 0.0056 & 0.0161 & -0.0029 & 0.0035 & 0.0005 & 0.844 \\
\hline $\mathrm{C} 5 \cdots \mathrm{N} 2$ & 3.392 & 0.8683 & 0.0050 & 0.0160 & -0.0028 & 0.0034 & 0.0006 & 0.817 \\
\hline $\mathrm{C} 5 \cdots \mathrm{N} 2$ & 3.417 & 0.8424 & 0.0049 & 0.0156 & -0.0027 & 0.0033 & 0.0006 & 0.815 \\
\hline $\mathrm{C} 9 \cdots \mathrm{N} 3$ & 3.407 & 0.8591 & 0.0052 & 0.0148 & -0.0027 & 0.0032 & 0.0005 & 0.850 \\
\hline $\mathrm{O} 1 \cdots \mathrm{H} 8$ & 2.360 & 2.0118 & 0.0096 & 0.0295 & -0.0064 & 0.0069 & 0.0005 & 0.930 \\
\hline $\mathrm{O} 2 \cdots \mathrm{H} 13$ & 2.552 & 1.3478 & 0.0068 & 0.0252 & -0.0043 & 0.0053 & 0.0010 & 0.811 \\
\hline $\mathrm{O} 2 \cdots \mathrm{H} 15$ & 2.083 & 3.8335 & 0.0156 & 0.0485 & -0.0122 & 0.0122 & -0.0001 & 1.004 \\
\hline $\mathrm{O} 2 \cdots \mathrm{H} 12$ & 2.450 & 1.7128 & 0.0084 & 0.0272 & -0.0055 & 0.0061 & 0.0007 & 0.890 \\
\hline \multicolumn{9}{|c|}{ Complex 2} \\
\hline $\mathrm{C} 25 \cdots \mathrm{H} 3$ & 2.632 & 1.0444 & 0.0071 & 0.0223 & -0.0033 & 0.0045 & 0.0011 & 0.747 \\
\hline $\mathrm{C} 31 \cdots \mathrm{H} 6$ & 2.650 & 0.9912 & 0.0068 & 0.0209 & -0.0032 & 0.0042 & 0.0010 & 0.753 \\
\hline $\mathrm{C} 10 \cdots \mathrm{H} 32$ & 2.697 & 0.7919 & 0.0055 & 0.0193 & -0.0025 & 0.0037 & 0.0012 & 0.686 \\
\hline $\mathrm{H} 34 \cdots \mathrm{O} 1$ & 2.323 & 2.7102 & 0.0111 & 0.0504 & -0.0086 & 0.0106 & 0.0020 & 0.814 \\
\hline $\mathrm{H} 16 \cdots \mathrm{O} 3$ & 2.332 & 2.4315 & 0.0104 & 0.0391 & -0.0077 & 0.0088 & 0.0010 & 0.885 \\
\hline $\mathrm{H} 12 \cdots \mathrm{O} 4$ & 2.444 & 1.7705 & 0.0084 & 0.0328 & -0.0056 & 0.0069 & 0.0013 & 0.815 \\
\hline $\mathrm{H} 9 \ldots \mathrm{O} 2$ & 2.486 & 1.7245 & 0.0086 & 0.0306 & -0.0055 & 0.0066 & 0.0011 & 0.836 \\
\hline Pt2 $\cdots H 29$ & 2.901 & 1.7245 & 0.0086 & 0.0306 & -0.0055 & 0.0066 & 0.0011 & 0.836 \\
\hline \multicolumn{9}{|c|}{ Complex 3} \\
\hline N4 $\cdots$ H14 & 2.273 & 2.5969 & 0.0122 & 0.0382 & -0.0083 & 0.0089 & 0.0006 & 0.929 \\
\hline N4 $\cdots$ H14 & 2.273 & 2.6064 & 0.0122 & 0.0381 & -0.0083 & 0.0089 & 0.0006 & 0.932 \\
\hline $\mathrm{H} 8 \cdots \mathrm{O} 2$ & 2.385 & 1.8904 & 0.0089 & 0.0313 & -0.0060 & 0.0069 & 0.0009 & 0.870 \\
\hline $\mathrm{H} 3 \cdots \mathrm{O} 2$ & 2.422 & 1.7526 & 0.0085 & 0.0284 & -0.0056 & 0.0063 & 0.0008 & 0.881 \\
\hline $\mathrm{H} 2 \cdots \mathrm{O} 2$ & 2.498 & 1.4290 & 0.0072 & 0.0250 & -0.0046 & 0.0054 & 0.0008 & 0.843 \\
\hline Pt1 $\cdots$ H16 & 2.650 & 2.2492 & 0.0114 & 0.0392 & -0.0072 & 0.0085 & 0.0013 & 0.845 \\
\hline Pt1 $\cdots$ H16 & 2.650 & 2.2517 & 0.0114 & 0.0392 & -0.0072 & 0.0085 & 0.0013 & 0.846 \\
\hline \multicolumn{9}{|c|}{ Complex 4} \\
\hline $\mathrm{C} 12 \cdots \mathrm{H} 9$ & 2.708 & 0.7821 & 0.0057 & 0.0186 & -0.0025 & 0.0036 & 0.0011 & 0.699 \\
\hline $\mathrm{H} 16 \cdots \mathrm{O} 2$ & 2.338 & 1.9276 & 0.0089 & 0.0303 & -0.0061 & 0.0069 & 0.0007 & 0.896 \\
\hline $\mathrm{H} 16 \cdots \mathrm{O} 2$ & 2.338 & 1.9242 & 0.0088 & 0.0305 & -0.0061 & 0.0069 & 0.0007 & 0.891 \\
\hline $\mathrm{H} 14 \cdots \mathrm{O} 2$ & 2.467 & 0.9670 & 0.0053 & 0.0218 & -0.0031 & 0.0043 & 0.0012 & 0.722 \\
\hline $\mathrm{H} 12 \ldots \mathrm{O} 1$ & 2.511 & 1.3375 & 0.0068 & 0.0235 & -0.0043 & 0.0051 & 0.0008 & 0.842 \\
\hline $\mathrm{H} 12 \ldots \mathrm{O} 1$ & 2.511 & 1.3392 & 0.0068 & 0.0237 & -0.0043 & 0.0051 & 0.0008 & 0.837 \\
\hline $\mathrm{H} 10 \cdots \mathrm{O} 1$ & 2.507 & 1.6330 & 0.0081 & 0.0303 & -0.0052 & 0.0064 & 0.0012 & 0.814 \\
\hline \multicolumn{9}{|c|}{ Complex 5} \\
\hline C17. . H19 & 2.699 & 0.9949 & 0.0069 & 0.0240 & -0.0032 & 0.0046 & 0.0014 & 0.692 \\
\hline $\mathrm{H} 4 \cdots \mathrm{O} 3$ & 2.396 & 1.6975 & 0.0080 & 0.0289 & -0.0054 & 0.0063 & 0.0009 & 0.856 \\
\hline $\mathrm{H} 4 \cdots \mathrm{O} 3$ & 2.396 & 1.7129 & 0.0081 & 0.0287 & -0.0055 & 0.0063 & 0.0009 & 0.863 \\
\hline $\mathrm{H} 24 \cdots \mathrm{O} 1$ & 2.461 & 1.5307 & 0.0075 & 0.0267 & -0.0049 & 0.0058 & 0.0009 & 0.844 \\
\hline $\mathrm{H} 25 \cdots \mathrm{O} 2$ & 2.556 & 1.3488 & 0.0069 & 0.0270 & -0.0043 & 0.0055 & 0.0012 & 0.777 \\
\hline H10 . O O5 & 2.324 & 2.2836 & 0.0103 & 0.0407 & -0.0073 & 0.0087 & 0.0015 & 0.834 \\
\hline $\mathrm{H} 23 \ldots \mathrm{O} 6$ & 2.278 & 2.5966 & 0.0118 & 0.0373 & -0.0083 & 0.0088 & 0.0005 & 0.941 \\
\hline $\mathrm{H} 23 \cdots \mathrm{O} 6$ & 2.278 & 2.6027 & 0.0118 & 0.0374 & -0.0083 & 0.0088 & 0.0005 & 0.940 \\
\hline
\end{tabular}


Table 2. Cont

\begin{tabular}{|c|c|c|c|c|c|c|c|c|}
\hline Contact Type & $D(\AA)$ & $\underset{(\mathrm{kcal} / \mathrm{mol})}{\mathrm{E}_{\mathrm{int}}}$ & $\begin{array}{c}\rho(r) \\
\left(e / a_{0}{ }^{3}\right)\end{array}$ & $\begin{array}{l}\nabla^{2} \rho(\mathrm{r}) \\
\left(\mathrm{e} / \mathrm{a}_{0}{ }^{5}\right)\end{array}$ & $\begin{array}{c}V(\mathbf{r}) \\
\text { (a.u.) }\end{array}$ & $\begin{array}{c}G(\mathrm{r}) \\
\text { (a.u.) }\end{array}$ & $\begin{array}{c}H(\text { r) } \\
\text { (a.u.) }\end{array}$ & $|V(\mathbf{r})| / G(\mathrm{r})$ \\
\hline \multicolumn{9}{|c|}{ Complex 6} \\
\hline $\mathrm{H} 9 \cdots \mathrm{F}$ & 2.544 & 1.1047 & 0.0050 & 0.0260 & -0.0035 & 0.0050 & 0.0015 & 0.703 \\
\hline $\mathrm{H} 10 \cdots \mathrm{F}$ & 2.526 & 1.1840 & 0.0054 & 0.0274 & -0.0038 & 0.0053 & 0.0015 & 0.711 \\
\hline $\mathrm{C} 16 \cdots \mathrm{H} 4$ & 2.669 & 0.9030 & 0.0063 & 0.0212 & -0.0029 & 0.0041 & 0.0012 & 0.704 \\
\hline $\mathrm{H} 8 \cdots \mathrm{O} 3$ & 2.360 & 1.8423 & 0.0087 & 0.0283 & -0.0059 & 0.0065 & 0.0006 & 0.907 \\
\hline $\mathrm{H} 8 \cdots \mathrm{O} 3$ & 2.360 & 1.8405 & 0.0087 & 0.0282 & -0.0059 & 0.0065 & 0.0006 & 0.908 \\
\hline $\mathrm{H} 6 \cdots \mathrm{O} 3$ & 2.503 & 0.5211 & 0.0031 & 0.0128 & -0.0017 & 0.0024 & 0.0008 & 0.683 \\
\hline $\mathrm{H} 5 \ldots \mathrm{O} 3$ & 2.478 & 1.5297 & 0.0076 & 0.0260 & -0.0049 & 0.0057 & 0.0008 & 0.858 \\
\hline $\mathrm{H} 5 \cdots \mathrm{O} 3$ & 2.478 & 1.5259 & 0.0076 & 0.0259 & -0.0049 & 0.0057 & 0.0008 & 0.857 \\
\hline $\mathrm{H} 14 \cdots \mathrm{O} 2$ & 2.278 & 2.5177 & 0.0114 & 0.0360 & -0.0080 & 0.0085 & 0.0005 & 0.943 \\
\hline $\mathrm{H} 13 \cdots \mathrm{O} 2$ & 2.346 & 2.3741 & 0.0108 & 0.0375 & -0.0076 & 0.0085 & 0.0009 & 0.893 \\
\hline $\mathrm{H} 11 \cdots \mathrm{O} 1$ & 2.332 & 2.2869 & 0.0104 & 0.0369 & -0.0073 & 0.0083 & 0.0010 & 0.883 \\
\hline
\end{tabular}

For the studied systems, the $\mathrm{O} \cdots \mathrm{H}$ hydrogen bonds had low $\rho(\mathrm{r})$ and positive $\nabla^{2} \rho(\mathrm{r})$ values, typical of hydrogen-bonded closed-shell interactions [35] and satisfying the criteria proposed by Popelier for hydrogen bond formation [36]. As shown in Table 2, the values of $\rho(\mathrm{r})$ at the BCPs range from $0.0031-0.0156 \mathrm{e} / \mathrm{a}_{0}{ }^{3}$, which falls within the typical range proposed by Popelier [33] for hydrogen-bonding interactions. In addition, the positive values of $\nabla^{2} \rho(r)$ for all interactions indicate that the electronic charges are depleted along the interatomic path; again, this is characteristic of closed-shell interactions, such as hydrogen bonds. We noted that the O2 $\cdots$ H15-N3 interaction in 1 has the highest $\rho(r)$ indicating the strongest hydrogen bonding interaction and the highest covalent character of the interactions studied. The hydrogen-bonding interaction energies $\left(E_{\text {int }}\right)$ calculated using the potential energy density $(V(\mathrm{r}))$ are listed in Table 2 . Correlation graphs between the $E_{\text {int }}$ and $\rho(\mathrm{r})$ are straight lines (Figure 9) with high correlation coefficients $\left(R^{2}=0.947\right)$, following the relationship $E_{\text {int }}=216.2 \rho(\mathrm{r})$, which agrees well with the equation of Parthasarathi [37]. A graphical plot of the hydrogen bond distance and $E_{\text {int }}$ gave the expected inverse linear relationship (Figure 9). Stronger hydrogen-bonding interactions with shorter hydrogen-bond distances are usually indicated by higher values of $\rho(r)$ at the BCP, indicating a more covalent hydrogen bond (Figure 9). Moreover, the contact distances plotted against $\rho(\mathrm{r})$ and $\nabla^{2} \rho(\mathrm{r})$ are shown in Figure 10. There is an inverse relationship between the hydrogen bond length and both $\rho(r)$ and $\nabla^{2} \rho(r)$. Furthermore, there is a general decrease in the electron density and the strength of the hydrogen bonds with increasing contact distance because the increase in the atomic separation results in reduced orbital overlap, decreasing the electron density along the bond path.
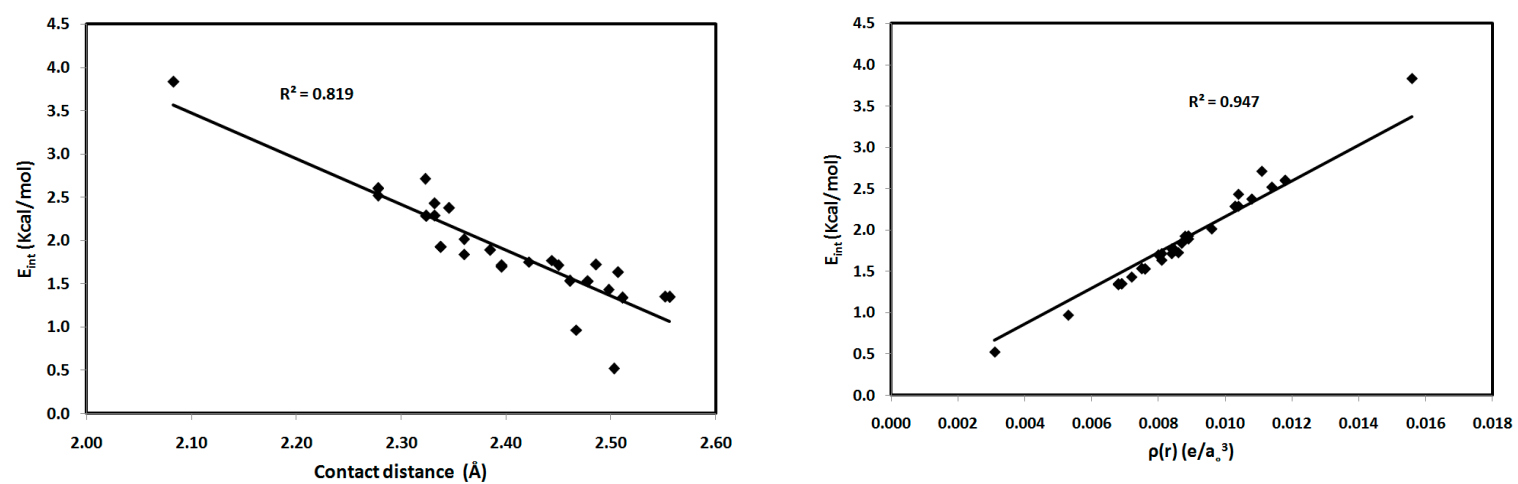

Figure 9. Interaction energies $\left(E_{\text {int }}\right)$ versus contact distances (left) and electron density $(\rho(\mathrm{r}))$ (right) for the studied systems. 

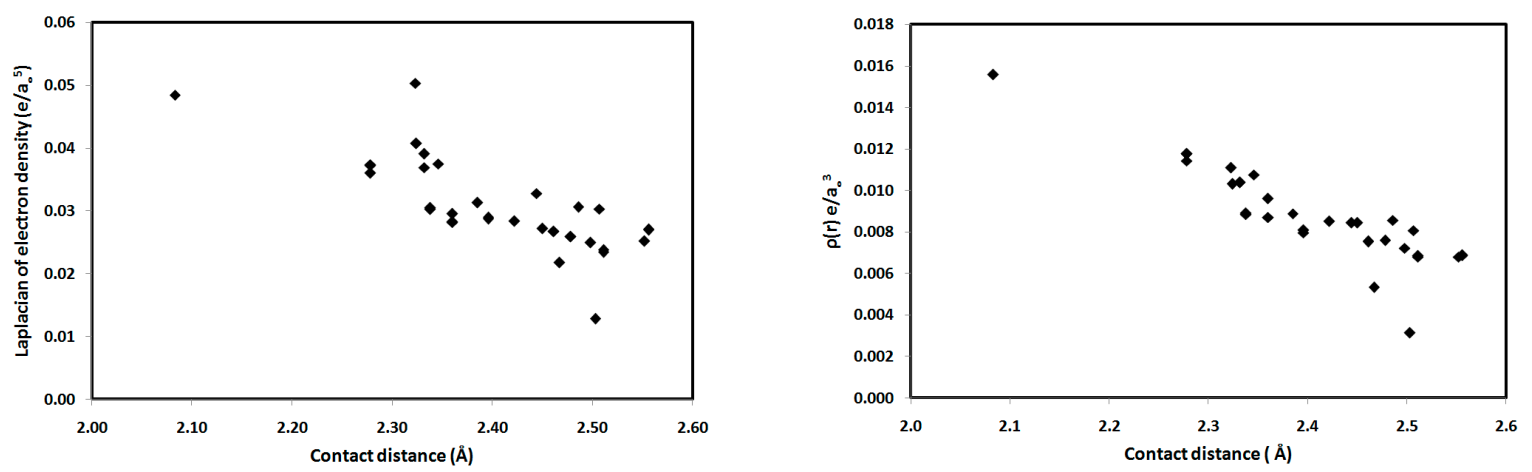

Figure 10. Contact distances versus the topological parameters $\nabla^{2} \rho(r)$ and $\rho(r)$ for the studied systems.

According to Rozas et al. [38], interactions may be classified based on the total electronic energy density, $H(\mathrm{r})$ and $\nabla^{2} \rho(\mathrm{r})$, which are indicative of the strength and the degree of covalency of the hydrogen bonds. The values $\nabla^{2} \rho(\mathrm{r})>0$ and $H(\mathrm{r})>0$ are indicative of weak hydrogen bonds that are mainly electrostatic in nature. In contrast, medium strength hydrogen bonds are characterized by $\nabla^{2} \rho(\mathrm{r})>0$ and $H(\mathrm{r})<0$, while, for strong hydrogen bonds, both $\nabla^{2} \rho(\mathrm{r})$ and $\mathrm{H}(\mathrm{r})$ are less than zero. Moreover, Espinosa et al. [39] used the ratio of the absolute potential energy density to the kinetic energy density $(|V(\mathrm{r})| / G(\mathrm{r}))$ to classify the bonding interactions. In their study, closed-shell interactions have a ratio of $|V(\mathrm{r})| / G(\mathrm{r})<1$, while shared interactions have a ratio of $|V(\mathrm{r})| / G(\mathrm{r})>2$. Bonded interactions with $|V(\mathrm{r})| / G(\mathrm{r})$ ratios between 1 and 2 are considered intermediate between these two extremes. As shown in Table 2, the absolute value of the potential energy density is, generally, smaller than the kinetic energy density; this results in $|V(\mathrm{r})| / G(\mathrm{r})$ ratios that range from 0.686 to 0.943 and are, in general, less than 1 . In addition, most interactions have $\nabla^{2} \rho(\mathrm{r})>0$ and $H(\mathrm{r})>0$ which are the typical characteristics of weak interactions, except for the N-H $\cdots$ O hydrogen bond in complex 1 . Therefore, based on the values $\nabla^{2} \rho(\mathrm{r})>0$ and $(H(\mathrm{r}))<0$, the $\mathrm{N}-\mathrm{H} \cdots \mathrm{O}$ interaction in $\mathbf{1}$ is a medium strength hydrogen bond with partially covalent character. In addition, the $\mathrm{N}-\mathrm{H} \cdots$ O hydrogen bond has a $|V(\mathrm{r})| / G(\mathrm{r})$ ratio slightly greater than $1(1.004)$. Therefore, the high covalency of this interaction is evident.

Other intermolecular interactions, such as the $\mathrm{C} \cdots \mathrm{H}, \mathrm{H} \cdots \mathrm{F}$, and $\mathrm{C} \cdots \mathrm{N}$, showed similar results, but, in general, the values of the $\rho(\mathrm{r}), \nabla^{2} \rho(\mathrm{r})$, and $E_{\text {int }}$ are lower than those for the $\mathrm{H} \cdots \mathrm{O}$ interactions. In addition, the $|V(\mathrm{r})| / G(\mathrm{r})$ ratios are very low for these interactions, which also have the lowest interaction energies; consequently, these interactions are considered weak and play a less important role in crystal packing than the previously discussed interactions. In contrast, complex 3 has significant $\mathrm{N} \cdots \mathrm{H}$ interactions which seem to be equivalent. The high values of $\rho(r), \nabla^{2} \rho(r)$, and $E_{\text {int }}$ are indicative of the importance of these interactions. In the crystal structures of complexes 2 and 3, Pt $\cdots H$ interactions are evident. Based on $\rho(r), \nabla^{2} \rho(r)$, and $E_{\text {int }}$, these interactions are slightly stronger in complex 3 than those in $\mathbf{2}$ because the $E_{\text {int }}$ values for the former are higher than that of the latter.

\subsection{NBO Charges}

Because we found that the $\mathrm{H} \cdots \mathrm{O}$ interactions are the most important intermolecular interactions in the crystal structures of the Pt complexes studied, we focus on studying these Hydrogen bonding interactions within the NBO framework. The formation of hydrogen bonds affects the charges of the atoms involved in these interactions, and the atomic charges of the hydrogen-bonded atoms are often different compared to those of atoms in the monomer or isolated molecules. Therefore, the atomic charges of the hydrogen-bonded atoms were investigated to give more insight into the electrostatic nature of the hydrogen bonds in the studied systems. The change in the charge of hydrogen-bonded atoms is a criterion used in the study of hydrogen bonding interactions. The hydrogen atom charges in the isolated complexes and cluster complexes were calculated by natural population analysis (NPA) 
using the NBO program implemented in G03, and the results are listed in Table 3. From this table, it is evident that the charges of the hydrogen atoms shifted to more positive values upon the formation of hydrogen bonds. The magnitude of this effect ranges from 0.0043 e to $0.0285 \mathrm{e}$ for most of the hydrogen-bonded complexes. Due to these interactions, the hydrogen acceptor atoms (A) in the clusters have more negative charge compared to those in the monomers (see Table 3). However, the charges at the donor atoms do not show a clear trend for all the studied systems. The absolute NBO charge differences $\left(\Delta \mathrm{N}_{\mathrm{A}} \cdots_{\mathrm{H}}\right)$ between intermolecular hydrogen-bond-forming atom $\mathrm{A}$ and the hydrogen atoms were obtained by taking absolute values of the difference between the charge of atom $\mathrm{A}$ and the charges of the hydrogen atoms, and these values are summarized in Table 3 . The calculated absolute NBO charge difference between intermolecular hydrogen bond-forming atoms $(\mathrm{A}, \mathrm{H})$ for the $\mathrm{O} \cdots \mathrm{H}-\mathrm{N}$ interaction is a maximum, and accordingly, from an electrostatic point of view this is the strongest hydrogen bond type, as shown in Table 3.

A more exhaustive NBO analysis of the complex clusters and monomers was made to more accurately estimate the nature of the hydrogen bonds in the studied systems. Table 4 shows the most important donor-acceptor interactions and their second-order perturbation energies, $E^{(2)}$. Estimations of the second-order perturbative charge-transfer (CT) energies listed in this table reveal the significant interactions between the lone pairs of the $\mathrm{H}$-acceptor atom $(\mathrm{A})$ to the $\mathrm{D}-\mathrm{H}$ antibonding $\left(\sigma^{*}\right)$ orbitals. In general, the CT interactions from the second lone pair of $\mathrm{A}$ to the antibonding $\sigma^{*}$ - orbital are larger than that of the first lone pair. Based on results collected in Table 4, among the interactions studied, the $\mathrm{N}-\mathrm{H} \cdots \mathrm{O}$ (complex 1 ) and $\mathrm{N}-\mathrm{H} \cdots \mathrm{N}($ complex 3$)$ interactions are the strongest, and their $E^{(2)}$ values were calculated to be 6.155 and $5.192 \mathrm{~kJ} / \mathrm{mol}$, respectively.

Due to the interactions between the NBOs of the D-H and an A atom or group, the occupancies and energies change significantly. The energies and occupancies of the donor and acceptor NBOs involved in these interactions compared to those of the monomer complex are listed in Table 4. Because most of the interactions involve electron donation from the hydrogen-bond acceptor atom (A) lone pair $\mathrm{NBO}$ to the $\sigma^{*}$-antibonding NBO of the D-H bond, compared to the monomer, the occupancy of the former decreases but increases for the latter. In addition, their energies are affected. The data presented in Table 4 reveal the criteria for all interactions where the occupancy of the $\sigma^{*}(\mathrm{D}-\mathrm{H})$ bond is increased and their energies are destabilized. In contrast, the energies of the donor NBOs lone pairs are stabilized. Notably, some of the $\mathrm{C}-\mathrm{H} \cdots \mathrm{O}$ and $\mathrm{N}-\mathrm{H} \cdots \mathrm{O}$ interactions not only originate from the $\mathrm{LP}(\mathrm{A}) \rightarrow \sigma^{*}(\mathrm{D}-\mathrm{H})$ interaction but from the filled $\pi$-NBO of the $\mathrm{C}=\mathrm{O}$ group to the $\sigma^{*}(\mathrm{D}-\mathrm{H})$ antibonding orbital.

In the case of the $\mathrm{Pt} \cdots \mathrm{H}$ interactions in complex 3, the donor $\mathrm{NBO}$ is from the filled lone pair $\mathrm{NBO}$ of the Pt atom to the antibonding $\sigma^{*} \mathrm{~N}-\mathrm{H}$ NBO. In these interactions, the NBO donor lone pair from the $\mathrm{Pt}$ as $\mathrm{H}$-acceptor has a high contribution from the $\mathrm{d}_{\mathrm{xy}}, \mathrm{d}_{\mathrm{xz}}$, and $\mathrm{s}$ atomic orbitals in the NBO hybrid. A representative example of the interactions between the NBOs involved in the hydrogen-bonding interactions is shown in Figure 11. Notably, Pt $\cdots \mathrm{H}$ interactions in 2 were not detected. 
Table 3. Calculated natural charges at the D-H . . A sites using the B3LYP functional.

\begin{tabular}{|c|c|c|c|c|c|c|c|c|c|c|c|}
\hline \multirow{2}{*}{$\begin{array}{c}\text { Contact Type } \\
\text { A } \cdots \text { H-D }\end{array}$} & \multirow{2}{*}{ A $\cdots$ D Distance } & \multicolumn{3}{|c|}{ Clusters } & \multicolumn{3}{|c|}{ Monomer Complex } & \multirow{2}{*}{$\Delta \mathrm{N}(\mathrm{H})$} & \multirow{2}{*}{$\Delta \mathrm{N}(\mathrm{D})$} & \multirow{2}{*}{$\Delta \mathrm{N}(\mathrm{A})$} & \multirow{2}{*}{$\Delta \mathbf{N}_{\mathrm{A}} \cdots \mathrm{H}_{\mathrm{H}}$} \\
\hline & & $\mathbf{H}$ & $\mathbf{D}$ & A & $\mathbf{H}$ & D & A & & & & \\
\hline \multicolumn{12}{|c|}{ Complex 1} \\
\hline $\mathrm{O} 1 \cdots \mathrm{H} 8-\mathrm{C} 8$ & 2.360 & 0.2028 & -0.0799 & -0.6605 & 0.1759 & -0.1090 & -0.6367 & 0.0269 & 0.0291 & -0.0238 & 0.8633 \\
\hline $\mathrm{O} 2 \cdots \mathrm{H} 13-\mathrm{C} 11$ & 2.552 & 0.2086 & -0.6004 & -0.6842 & 0.1957 & -0.5904 & -0.6214 & 0.0129 & -0.01 & -0.0628 & 0.8928 \\
\hline $\mathrm{O} 2 \cdots \mathrm{H} 15-\mathrm{N} 3$ & 2.083 & 0.3281 & -0.4735 & -0.6842 & 0.3075 & -0.4708 & -0.6214 & 0.0206 & -0.0027 & -0.0628 & 1.0123 \\
\hline $\mathrm{O} 2 \cdots \mathrm{H} 12-\mathrm{C} 11$ & 2.450 & 0.2334 & -0.5976 & -0.6842 & 0.2063 & -0.5904 & -0.6214 & 0.0271 & -0.0072 & -0.0628 & 0.9176 \\
\hline \multicolumn{12}{|c|}{ Complex 2} \\
\hline $\mathrm{C} 25 \cdots \mathrm{H} 3-\mathrm{C} 2$ & 2.632 & 0.1977 & -0.6472 & -0.2038 & 0.2010 & -0.6467 & -0.2015 & -0.0033 & -0.0005 & -0.0023 & 0.4015 \\
\hline $\mathrm{C} 31 \cdots \mathrm{H} 6-\mathrm{C} 4$ & 2.650 & 0.2074 & -0.6601 & -0.1517 & 0.2001 & -0.6522 & -0.1503 & 0.0073 & -0.0079 & -0.0014 & 0.3591 \\
\hline $\mathrm{C} 10 \cdots \mathrm{H} 32-\mathrm{C} 32$ & 2.697 & 0.1847 & -0.1590 & 0.1273 & 0.1781 & -0.1622 & 0.1328 & 0.0066 & 0.0032 & -0.0055 & 0.0574 \\
\hline O1 $\cdots$ H34-N6 & 2.323 & 0.3398 & -0.4528 & -0.6923 & 0.3213 & -0.4543 & -0.6528 & 0.0185 & 0.0015 & -0.0395 & 1.0321 \\
\hline O3 $\cdots$ H16-N3 & 2.332 & 0.3363 & -0.4663 & -0.6757 & 0.3219 & -0.4670 & -0.6523 & 0.0144 & 0.0007 & -0.0234 & 1.0120 \\
\hline $\mathrm{O} 4 \cdots \mathrm{H} 12-\mathrm{C} 13$ & 2.444 & 0.1911 & -0.1293 & -0.6149 & 0.1733 & -0.1497 & -0.6009 & 0.0178 & 0.0204 & -0.014 & 0.8060 \\
\hline $\mathrm{O} 2 \cdots \mathrm{H} 9-\mathrm{C} 9$ & 2.486 & 0.1938 & -0.1778 & -0.6341 & 0.1813 & -0.1954 & -0.5979 & 0.0125 & 0.0176 & -0.0362 & 0.8279 \\
\hline \multicolumn{12}{|c|}{ Complex 3} \\
\hline $\mathrm{O} 2 \cdots \mathrm{H} 8-\mathrm{C} 7$ & 2.385 & 0.2367 & -0.6048 & -0.6671 & 0.2082 & -0.5996 & -0.6323 & 0.0285 & -0.0052 & -0.0348 & 0.9038 \\
\hline $\mathrm{O} 2 \cdots \mathrm{H} 3-\mathrm{C} 2$ & 2.422 & 0.2102 & -0.6570 & -0.6671 & 0.2015 & -0.6499 & -0.6323 & 0.0087 & -0.0071 & -0.0348 & 0.8773 \\
\hline $\mathrm{O} 2 \cdots \mathrm{H} 2-\mathrm{C} 2$ & 2.498 & 0.2231 & -0.6637 & -0.6671 & 0.2051 & -0.6499 & -0.6323 & 0.0180 & -0.0138 & -0.0348 & 0.8902 \\
\hline Pt1 $\cdots$ H16-N4 & 2.650 & 0.3253 & -0.4924 & 0.4082 & 0.3043 & -0.4907 & 0.4225 & 0.0210 & -0.0017 & -0.0143 & 0.0829 \\
\hline Pt1 $\cdots$ H16-N4 & 2.650 & 0.3199 & -0.4881 & 0.4136 & 0.3043 & -0.4907 & 0.4225 & 0.0156 & 0.0026 & -0.0089 & 0.0937 \\
\hline \multicolumn{12}{|c|}{ Complex 4} \\
\hline $\mathrm{C} 12 \cdots \mathrm{H} 9-\mathrm{C} 8$ & 2.708 & 0.1792 & -0.1077 & -0.2004 & 0.1749 & -0.1088 & 0.1817 & 0.0043 & 0.0011 & -0.3821 & 0.3796 \\
\hline $\mathrm{O} 2 \cdots \mathrm{H} 16-\mathrm{C} 16$ & 2.338 & 0.1910 & -0.2396 & -0.6429 & 0.1742 & -0.2277 & -0.5938 & 0.0168 & -0.0119 & -0.0491 & 0.8339 \\
\hline $\mathrm{O} 2 \cdots \mathrm{H} 16-\mathrm{C} 16$ & 2.338 & 0.1925 & -0.2367 & -0.6461 & 0.1742 & -0.2277 & -0.5938 & 0.0183 & -0.009 & -0.0523 & 0.8386 \\
\hline $\mathrm{O} 2 \cdots \mathrm{H} 14-\mathrm{C} 14$ & 2.467 & 0.1817 & -0.1455 & -0.6429 & 0.1712 & -0.1799 & -0.5938 & 0.0105 & 0.0344 & -0.0491 & 0.8246 \\
\hline $\mathrm{O} 1 \cdots \mathrm{H} 12-\mathrm{C} 12$ & 2.511 & 0.1933 & -0.1915 & -0.6827 & 0.1817 & -0.1856 & -0.6594 & 0.0116 & -0.0059 & -0.0233 & 0.8760 \\
\hline $\mathrm{O} 1 \cdots \mathrm{H} 12-\mathrm{C} 12$ & 2.511 & 0.1959 & -0.2010 & -0.6797 & 0.1817 & -0.1856 & -0.6594 & 0.0142 & -0.0154 & -0.0203 & 0.8756 \\
\hline $\mathrm{O} 1 \cdots \mathrm{H} 10-\mathrm{C} 9$ & 2.507 & 0.1895 & -0.1959 & -0.6827 & 0.1820 & -0.1986 & -0.6594 & 0.0075 & 0.0027 & -0.0233 & 0.8722 \\
\hline
\end{tabular}


Table 3. Calculated natural charges at the D-H . . A sites using the B3LYP functional.

\begin{tabular}{|c|c|c|c|c|c|c|c|c|c|c|c|}
\hline \multirow{2}{*}{$\begin{array}{c}\text { Contact Type } \\
\text { A } \cdots \text { H-D }\end{array}$} & \multirow{2}{*}{ A... D Distance } & \multicolumn{3}{|c|}{ Clusters } & \multicolumn{3}{|c|}{ Monomer Complex } & \multirow{2}{*}{$\Delta \mathrm{N}(\mathrm{H})$} & \multirow{2}{*}{$\Delta \mathrm{N}(\mathrm{D})$} & \multirow{2}{*}{$\Delta \mathrm{N}(\mathrm{A})$} & \multirow{2}{*}{$\Delta \mathrm{N}_{\mathrm{A}} \cdots_{\mathrm{H}}$} \\
\hline & & $\mathbf{H}$ & D & A & $\mathbf{H}$ & D & A & & & & \\
\hline \multicolumn{12}{|c|}{ Complex 5} \\
\hline C17 * H19-C16 & 2.699 & 0.2109 & -0.6558 & 0.0684 & 0.2040 & -0.6470 & 0.0832 & 0.0069 & -0.0088 & -0.0148 & 0.1425 \\
\hline $\mathrm{O} 3 \cdots \mathrm{H} 4-\mathrm{C} 4$ & 2.396 & 0.2193 & -0.6544 & -0.6382 & 0.1982 & -0.6486 & -0.6272 & 0.02112 & -0.0058 & -0.01103 & 0.8576 \\
\hline $\mathrm{O} 3 \cdots \mathrm{H} 4-\mathrm{C} 4$ & 2.396 & 0.2193 & -0.6544 & -0.6382 & 0.1982 & -0.6486 & -0.6272 & 0.02112 & -0.0058 & -0.01103 & 0.8576 \\
\hline $\mathrm{O} 1 \cdots \mathrm{H} 24-\mathrm{C} 20$ & 2.461 & 0.1886 & -0.0996 & -0.6982 & 0.1777 & -0.1017 & -0.6724 & 0.0109 & 0.0021 & -0.0258 & 0.8868 \\
\hline $\mathrm{O} 2 \cdots \mathrm{H} 25-\mathrm{C} 21$ & 2.556 & 0.1986 & -0.1619 & -0.6303 & 0.1825 & -0.1879 & -0.5975 & 0.0161 & 0.026 & -0.0328 & 0.8289 \\
\hline $\mathrm{O} 6 \cdots \mathrm{H} 23-\mathrm{C} 19$ & 2.278 & 0.2010 & -0.1787 & -0.6460 & 0.1877 & -0.1816 & -0.6144 & 0.0133 & 0.0029 & -0.0316 & 0.8470 \\
\hline O6 $\cdots$ H23-C19 & 2.278 & 0.2034 & -0.1742 & -0.6452 & 0.1877 & -0.1816 & -0.6144 & 0.0157 & 0.0074 & -0.0308 & 0.8486 \\
\hline \multicolumn{12}{|c|}{ Complex 6} \\
\hline H9. . F-C15 & 2.544 & 0.1890 & -0.1830 & -0.3625 & 0.1827 & -0.1849 & -0.3451 & 0.0063 & 0.0019 & -0.0174 & 0.5515 \\
\hline $\mathrm{H} 10 \cdots \mathrm{F}-\mathrm{C} 15$ & 2.526 & 0.1824 & -0.0970 & -0.3625 & 0.1774 & -0.1078 & -0.3451 & 0.0050 & 0.0108 & -0.0174 & 0.5449 \\
\hline $\mathrm{C} 16 \cdots \mathrm{H} 4-\mathrm{C} 4$ & 2.669 & 0.1960 & -0.6500 & -0.2518 & 0.1910 & -0.6513 & -0.2459 & 0.0050 & 0.0013 & -0.0059 & 0.4478 \\
\hline $\mathrm{O} 3 \cdots \mathrm{H} 8-\mathrm{C} 7$ & 2.360 & 0.2067 & -0.1633 & -0.6540 & 0.1862 & -0.1730 & -0.6268 & 0.0205 & 0.0097 & -0.0272 & 0.8607 \\
\hline $\mathrm{O} 3 \cdots \mathrm{H} 8-\mathrm{C} 7$ & 2.360 & 0.2028 & -0.1665 & -0.6450 & 0.1862 & -0.1730 & -0.6268 & 0.0166 & 0.0065 & -0.0182 & 0.8478 \\
\hline $\mathrm{O} 3 \cdots \mathrm{H} 5-\mathrm{C} 4$ & 2.478 & 0.2055 & -0.6528 & -0.6331 & 0.1938 & -0.6513 & -0.6268 & 0.0117 & -0.0015 & -0.0063 & 0.8386 \\
\hline $\mathrm{O} 2 \cdots \mathrm{H} 14-\mathrm{C} 16$ & 2.278 & 0.2137 & -0.2478 & -0.6088 & 0.1917 & -0.2459 & -0.5928 & 0.0220 & -0.0019 & -0.016 & 0.8225 \\
\hline $\mathrm{O} 2 \cdots \mathrm{H} 13-\mathrm{C} 14$ & 2.346 & 0.2167 & -0.2310 & -0.6240 & 0.1930 & -0.2377 & -0.5928 & 0.0237 & 0.0067 & -0.0312 & 0.8407 \\
\hline $\mathrm{O} 1 \cdots \mathrm{H} 11-\mathrm{C} 10$ & 2.332 & 0.1852 & 0.1362 & -0.6918 & 0.1715 & 0.1394 & -0.6786 & 0.0137 & -0.0032 & -0.0132 & 0.8770 \\
\hline
\end{tabular}


Table 4. Natural bond orbitals (NBOs) involved in the intermolecular interactions, their occupancies, energies (a.u.), and the second-order perturbation energies, $E^{(2)},(\mathrm{KJ} / \mathrm{mol})$.

\begin{tabular}{|c|c|c|c|c|c|c|c|c|}
\hline Contact type A $\cdots$ H-D & A...D Dist. & (NBO) i & (Occupancy) i & $E_{\mathrm{i}}$ & (NBO) $j$ & (Occupancy) j & $E_{\mathrm{j}}$ & $E^{(2)}$ \\
\hline \multicolumn{9}{|c|}{ Complex 1} \\
\hline \multirow[t]{2}{*}{$\mathrm{O} 1 \cdots \mathrm{H} 8-\mathrm{C} 8$} & 2.360 & $\mathrm{LP}(1) \mathrm{O} 1$ & 1.97137 (1.97169) & $-0.66824(-0.64828)$ & $\sigma^{*}(\mathrm{C} 8-\mathrm{H} 8)$ & $0.01397(0.01265)$ & $0.71211(0.66653)$ & 0.628 \\
\hline & & $\mathrm{LP}(2) \mathrm{O} 1$ & $1.86311(1.85818)$ & $-0.26356(-0.24078)$ & $\sigma^{*}(\mathrm{C} 8-\mathrm{H} 8)$ & $0.01397(0.01265)$ & $0.71211(0.66653)$ & 2.261 \\
\hline $\mathrm{O} 2 \cdots \mathrm{H} 13-\mathrm{C} 11$ & 2.552 & $\pi(\mathrm{C} 3-\mathrm{O} 2)$ & $1.99011(0.53040)$ & $-0.36890(-0.33956)$ & $\sigma^{*}(\mathrm{C} 11-\mathrm{H} 13)$ & $0.00788(0.00670)$ & $0.55924(0.53040)$ & 1.005 \\
\hline \multirow[t]{3}{*}{$\mathrm{O} 2 \cdots \mathrm{H} 15-\mathrm{N} 3$} & 2.083 & $\mathrm{LP}(1) \mathrm{O} 2$ & $1.97123(0.73470)$ & $-0.67080(0.73470)$ & $\sigma^{*}(\mathrm{~N} 3-\mathrm{H} 15)$ & $0.01347(0.73470)$ & $0.78719(0.73470)$ & 2.386 \\
\hline & & $\mathrm{LP}(2) \mathrm{O} 2$ & $1.87487(1.86076)$ & $-0.26693(-0.23237)$ & $\sigma^{*}(\mathrm{~N} 3-\mathrm{H} 15)$ & $0.01347(0.00912)$ & $0.78719(0.73470)$ & 6.155 \\
\hline & & $\pi(\mathrm{C} 3=\mathrm{O} 2)$ & 1.99011 (1.98993) & $-0.36890(-0.33956)$ & $\sigma^{*}(\mathrm{~N} 3-\mathrm{H} 15)$ & $0.01347(0.00912)$ & $0.78719(0.73470)$ & 0.544 \\
\hline \multirow[t]{2}{*}{$\mathrm{O} 2 \cdots \mathrm{H} 12-\mathrm{C} 11$} & 2.450 & $\mathrm{LP}(1) \mathrm{O} 2$ & $1.97123(1.97351)$ & $-0.67080(-0.64215)$ & $\sigma^{*}(\mathrm{C} 11-\mathrm{H} 12)$ & $0.01168(0.00886)$ & $0.57514(0.52857)$ & 0.628 \\
\hline & & $\mathrm{LP}(2) \mathrm{O} 2$ & $1.87487(1.86076)$ & $-0.26693(-0.23237)$ & $\sigma^{*}(\mathrm{C} 11-\mathrm{H} 12)$ & $0.01168(0.00886)$ & $0.57514(0.52857)$ & 2.680 \\
\hline \multicolumn{9}{|c|}{ Complex 2} \\
\hline $\mathrm{C} 25 \cdots \mathrm{H} 3-\mathrm{C} 2$ & 2.632 & $\pi(\mathrm{C} 25-\mathrm{C} 26)$ & $1.63140(1.63245)$ & $-0.27948(-0.29051)$ & $\sigma^{*}(\mathrm{C} 2-\mathrm{H} 3)$ & $0.00867(0.00810)$ & $0.59404(0.59837)$ & 1.214 \\
\hline $\mathrm{C} 31 \cdots \mathrm{H} 6-\mathrm{C} 4$ & 2.650 & $\pi(\mathrm{C} 31-\mathrm{C} 32)$ & $1.64661(1.65943)$ & $-0.26358(-0.27596)$ & $\sigma^{*}(\mathrm{C} 4-\mathrm{H} 6)$ & $0.00826(0.00734)$ & $0.59477(0.58464)$ & 1.382 \\
\hline \multirow[t]{2}{*}{$\mathrm{C} 10 \cdots \mathrm{H} 32-\mathrm{C} 32$} & 2.697 & $\sigma(\mathrm{C} 32-\mathrm{H} 32)$ & 1.97739 (1.97819) & $-0.57490(-0.58925)$ & $\pi^{*}(\mathrm{C} 10-\mathrm{N} 2)$ & $0.43750(0.43608)$ & $-0.03118(-0.04048)$ & 0.586 \\
\hline & & $\pi(\mathrm{C} 10-\mathrm{N} 2)$ & $1.76913(1.75890)$ & $-0.33656(-0.34197)$ & $\sigma^{*}(\mathrm{C} 32-\mathrm{H} 32)$ & $0.01374(0.01350)$ & $0.69918(0.67576)$ & 0.586 \\
\hline \multirow[t]{2}{*}{ O1 $\cdots$ H34-N6 } & 2.323 & $\mathrm{LP}(1) \mathrm{O} 1$ & $1.97191(1.97185)$ & $-0.66711(-0.65175)$ & $\sigma^{*}(\mathrm{~N} 6-\mathrm{H} 34)$ & $0.01218(0.01182)$ & $0.80595(0.77963)$ & 0.209 \\
\hline & & $\mathrm{LP}(2) \mathrm{O} 1$ & $1.88227(1.87315)$ & $-0.25176(-0.23319)$ & $\sigma^{*}(\mathrm{~N} 6-\mathrm{H} 34)$ & $0.01218(0.01182)$ & $0.80595(0.77963)$ & 0.879 \\
\hline \multirow[t]{2}{*}{ O3 $\cdots$ H16-N3 } & 2.332 & $\pi(\mathrm{C} 17-\mathrm{O} 3)$ & $1.98910(1.98983)$ & $-0.35705(-0.33828)$ & $\sigma^{*}(\mathrm{~N} 3-\mathrm{H} 17)$ & $0.01256(0.01108)$ & $0.74628(0.71888)$ & 0.795 \\
\hline & & $\mathrm{LP}(2) \mathrm{O} 3$ & 1.87408 (1.86995) & $-0.25616(-0.23664)$ & $\sigma^{*}(\mathrm{~N} 3-\mathrm{H} 17)$ & $0.01256(0.01108)$ & $0.74628(0.71888)$ & 0.963 \\
\hline $\mathrm{O} 4 \cdots \mathrm{H} 12-\mathrm{C} 13$ & 2.444 & $\mathrm{LP}(2) \mathrm{O} 4$ & $1.85563(1.85073)$ & $-0.24363(-0.23150)$ & $\sigma^{*}(\mathrm{C} 13-\mathrm{H} 12)$ & $0.01286(0.01281)$ & $0.72157(0.68308)$ & 0.461 \\
\hline $\mathrm{O} 2 \cdots \mathrm{H} 9-\mathrm{C} 9$ & 2.486 & $\mathrm{LP}(2) \mathrm{O} 2$ & $1.84626(1.84547)$ & $-0.23524(-0.23060)$ & $\sigma^{*}(\mathrm{C} 9-\mathrm{H} 9)$ & $0.01214(0.01129)$ & $0.65796(0.66930)$ & 0.712 \\
\hline \multicolumn{9}{|c|}{ Complex 3} \\
\hline N4 $\cdots$ H14-N3 & 2.273 & $\mathrm{LP}(1) \mathrm{N} 4$ & $1.85986(1.84172)$ & $-0.36581(-0.34055)$ & $\sigma^{*}(\mathrm{~N} 3-\mathrm{H} 14)$ & $0.01164(0.00884)$ & $0.81339(0.78729)$ & 5.192 \\
\hline N4 $\cdots$ H14-N3 & 2.273 & LP (1)N4 & $1.86168(1.84172)$ & $-0.35759(-0.34055)$ & $\sigma^{*}(\mathrm{~N} 3-\mathrm{H} 14)$ & $0.01161(0.00884)$ & $0.82344(0.78729)$ & 5.192 \\
\hline \multirow[t]{2}{*}{$\mathrm{O} 2 \cdot \cdots \mathrm{H} 8-\mathrm{C} 7$} & 2.385 & $\mathrm{LP}(1) \mathrm{O} 2$ & $1.97169(1.97261)$ & $-0.66099(-0.64978)$ & $\sigma^{*}(\mathrm{C} 7-\mathrm{H} 8)$ & $0.01186(0.01044)$ & $0.58379(0.52851)$ & 1.675 \\
\hline & & $\mathrm{LP}(2) \mathrm{O} 2$ & 1.86505 (1.85902) & $-0.25512(-0.24097)$ & $\sigma^{*}(\mathrm{C} 7-\mathrm{H} 8)$ & $0.01186(0.01044)$ & $0.58379(0.52851)$ & 0.963 \\
\hline \multirow[t]{3}{*}{$\mathrm{O} 2 \cdot \cdots \mathrm{H} 3-\mathrm{C} 2$} & 2.422 & $\mathrm{LP}(1) \mathrm{O} 2$ & $1.97169(1.97261)$ & $-0.66099(-0.64978)$ & $\sigma^{*}(\mathrm{C} 2-\mathrm{H} 3)$ & $0.01035(0.00768)$ & $0.62219(0.60008)$ & 0.293 \\
\hline & & $\mathrm{LP}(2) \mathrm{O} 2$ & 1.86505 (1.85902) & $-0.25512(-0.24097)$ & $\sigma^{*}(\mathrm{C} 2-\mathrm{H} 3)$ & $0.01035(0.00768)$ & $0.62219(0.60008)$ & 1.005 \\
\hline & & $\pi(\mathrm{C} 3-\mathrm{O} 2)$ & $1.99010(1.99023)$ & $-0.36459(-0.35580)$ & $\sigma^{*}(\mathrm{C} 2-\mathrm{H} 3)$ & $0.01035(0.00768)$ & $0.62219(0.60008)$ & 1.424 \\
\hline \multirow[t]{2}{*}{$\mathrm{O} 2 \cdots \mathrm{H} 2-\mathrm{C} 2$} & 2.498 & $\mathrm{LP}(1) \mathrm{O} 2$ & $1.97169(1.97261)$ & $-0.66099(-0.64978)$ & $\sigma^{*}(\mathrm{C} 2-\mathrm{H} 2)$ & $0.00979(0.00743)$ & $0.61830(0.58366)$ & 1.005 \\
\hline & & $\mathrm{LP}(2) \mathrm{O} 2$ & 1.86505 (1.85902) & $-0.25512(-0.24097)$ & $\sigma^{*}(\mathrm{C} 2-\mathrm{H} 2)$ & $0.00979(0.00743)$ & $0.61830(0.58366)$ & 1.633 \\
\hline Pt1 $\cdots$ H16-N4 & 2.650 & LP(1)Pt1 & $1.87880(1.99158)$ & $-0.26130(-0.24303)$ & $\sigma^{*}(\mathrm{~N} 4-\mathrm{H} 16)$ & $0.01058(0.00839)$ & $0.77742(0.74610)$ & 4.061 \\
\hline Pt1 $\cdots$ H16-N4 & 2.650 & LP(1)Pt1 & $1.91600(1.91561)$ & $-0.46068(-0.45392)$ & $\sigma^{*}(\mathrm{~N} 4-\mathrm{H} 16)$ & $0.01057(0.00839)$ & $0.76746(0.74610)$ & 3.894 \\
\hline
\end{tabular}


Table 4. Cont

\begin{tabular}{|c|c|c|c|c|c|c|c|c|}
\hline Contact type A $\cdots$ H-D & A $\cdots$ D Dist. & (NBO) i & (Occupancy) i & $E_{\mathrm{i}}$ & $(\mathrm{NBO}) \mathrm{j}$ & (Occupancy) j & $E_{\mathrm{j}}$ & $E^{(2)}$ \\
\hline \multicolumn{9}{|c|}{ Complex 4} \\
\hline \multirow[t]{2}{*}{$\mathrm{C} 12 \cdots \mathrm{H} 9-\mathrm{C} 8$} & 2.708 & $\sigma(\mathrm{C} 8-\mathrm{H} 9)$ & 1.97880 (1.97943) & $-0.59280(-0.60808)$ & $\pi^{*}(\mathrm{C} 12-\mathrm{C} 13)$ & $0.01734(0.30861)$ & $0.57893(0.02913)$ & 0.461 \\
\hline & & $\pi(\mathrm{C} 12-\mathrm{C} 13)$ & $1.97514(1.97564)$ & $-0.71226(-0.69807)$ & $\sigma^{*}(\mathrm{C} 8-\mathrm{H} 9)$ & $0.01350(0.01312)$ & $0.69110(0.66991)$ & 0.419 \\
\hline \multirow[t]{2}{*}{$\mathrm{O} 2 \cdots \mathrm{H} 16-\mathrm{C} 16$} & 2.338 & $\pi(\mathrm{C} 3-\mathrm{O} 2)$ & 1.98923 (1.98983) & $-0.38610(-0.35347)$ & $\sigma^{*}(\mathrm{C} 16-\mathrm{H} 16)$ & $0.01424(0.01304)$ & $0.69995(0.67898)$ & 1.549 \\
\hline & & $\mathrm{LP}(1) \mathrm{O} 2$ & 1.97068 (1.97264) & $-0.67192(-0.63955)$ & $\sigma^{*}(\mathrm{C} 16-\mathrm{H} 16)$ & $0.01424(0.01304)$ & 0.69995 (0.67898) & 1.089 \\
\hline \multirow[t]{2}{*}{$\mathrm{O} 2 \cdots \mathrm{H} 16-\mathrm{C} 16$} & 2.338 & $\pi(\mathrm{C} 3-\mathrm{O} 2)$ & 1.98947 (1.98983) & $-0.37977(-0.35347)$ & $\sigma^{*}(\mathrm{C} 16-\mathrm{H} 16)$ & $0.01423(0.01304)$ & $0.69933(0.67898)$ & 1.591 \\
\hline & & $\mathrm{LP}(1) \mathrm{O} 2$ & $1.97110(1.97264)$ & $-0.66751(-0.63955)$ & $\sigma^{*}(\mathrm{C} 16-\mathrm{H} 16)$ & $0.01423(0.01304)$ & $0.69933(0.67898)$ & 1.089 \\
\hline $\mathrm{O} 2 \cdots \mathrm{H} 14-\mathrm{C} 14$ & 2.467 & $\mathrm{LP}(1) \mathrm{O} 2$ & 1.97068 (1.97264) & $-0.67192(-0.63955)$ & $\sigma^{*}(\mathrm{C} 14-\mathrm{H} 14)$ & $0.01283(0.01256)$ & $0.72291(0.69606)$ & 0.419 \\
\hline \multirow[t]{2}{*}{$\mathrm{O} 1 \cdots \mathrm{H} 12-\mathrm{C} 12$} & 2.511 & $\mathrm{LP}(1) \mathrm{O} 1$ & 1.96440 (1.99026) & $-0.69115(-0.35247)$ & $\sigma^{*}(\mathrm{C} 12-\mathrm{H} 12)$ & $0.01253(0.01158)$ & $0.70138(0.68580)$ & 0.544 \\
\hline & & $\mathrm{LP}(2) \mathrm{O} 1$ & 1.86902 (1.86203) & $-0.28550(-0.25502)$ & $\sigma^{*}(\mathrm{C} 12-\mathrm{H} 12)$ & $0.01253(0.01158)$ & $0.70138(0.68580)$ & 0.502 \\
\hline \multirow[t]{2}{*}{$\mathrm{O} 1 \cdots \mathrm{H} 12-\mathrm{C} 12$} & 2.511 & $\mathrm{LP}(1) \mathrm{O} 1$ & 1.96527 (1.99026) & $-0.68160(-0.35247)$ & $\sigma^{*}(\mathrm{C} 12-\mathrm{H} 12)$ & $0.01253(0.01158)$ & $0.70098(0.68580)$ & 0.544 \\
\hline & & $\mathrm{LP}(2) \mathrm{O} 1$ & 1.86794 (1.86203) & $-0.27517(-0.25502)$ & $\sigma^{*}(\mathrm{C} 12-\mathrm{H} 12)$ & $0.01253(0.01158)$ & $0.70098(0.68580)$ & 0.544 \\
\hline $\mathrm{O} 1 \cdots \mathrm{H} 10-\mathrm{C} 9$ & 2.507 & $\mathrm{LP}(2) \mathrm{O} 1$ & $1.86902(1.86203)$ & $-0.28550(-0.25502)$ & $\sigma^{*}(\mathrm{C} 9-\mathrm{H} 10)$ & $0.01279(0.01193)$ & $0.68180(0.66621)$ & 0.419 \\
\hline \multicolumn{9}{|c|}{ Complex 5} \\
\hline \multirow[t]{2}{*}{ C17 * H19-C16 } & 2.699 & $\sigma(\mathrm{C} 16-\mathrm{H} 19)$ & 1.96707 (1.96868) & $-0.54074(-0.53534)$ & $\pi^{*}(\mathrm{C} 17-\mathrm{N} 4)$ & $0.01548(0.25607)$ & $0.54744(-0.03872)$ & 1.130 \\
\hline & & $\pi(\mathrm{C} 17-\mathrm{N} 4)$ & 1.98824 (1.92080) & $-0.91673(-0.37610)$ & $\sigma^{*}(\mathrm{C} 16-\mathrm{H} 19)$ & $0.00922(0.00877)$ & $0.57426(0.57142)$ & 0.377 \\
\hline \multirow[t]{2}{*}{$\mathrm{O} 3 \cdots \mathrm{H} 4-\mathrm{C} 4$} & 2.396 & $\pi(\mathrm{C} 11-\mathrm{O} 3)$ & 1.98337 (1.99523) & $(-0.39427)(-1.06665)$ & $\sigma^{*}(\mathrm{C} 4-\mathrm{H} 4)$ & $0.00963(0.00835)$ & $0.59373(0.56896)$ & 0.7534 \\
\hline & & $\mathrm{LP}(1) \mathrm{O} 3$ & 1.97713 (1.97866) & $(-0.70347)(-0.69621)$ & $\sigma^{*}(\mathrm{C} 4-\mathrm{H} 4)$ & $0.00963(0.00835)$ & $0.59373(0.56896)$ & 1.6324 \\
\hline \multirow[t]{2}{*}{$\mathrm{O} 3 \cdots \mathrm{H} 4-\mathrm{C} 4$} & 2.396 & $\pi(\mathrm{C} 11-\mathrm{O} 3)$ & 1.98337 (1.99523) & $(-0.39427)(-1.06665)$ & $\sigma^{*}(\mathrm{C} 4-\mathrm{H} 4)$ & $0.00963(0.00835)$ & $0.59373(0.56896)$ & 0.7534 \\
\hline & & $\mathrm{LP}(1) \mathrm{O} 3$ & 1.97713 (1.97866) & $-0.70347(-0.69621)$ & $\sigma^{*}(\mathrm{C} 4-\mathrm{H} 4)$ & $0.00963(0.00835)$ & $0.59373(0.56896)$ & 1.6324 \\
\hline \multirow[t]{2}{*}{$\mathrm{O} 1 \cdots \mathrm{H} 24-\mathrm{C} 20$} & 2.461 & LP(1)O1 & 1.96648 (1.96689) & $-0.68368(-0.67330)$ & $\sigma^{*}(\mathrm{C} 20-\mathrm{H} 24)$ & $0.01276(0.01209)$ & 0.70137 (0.66118) & 0.7540 \\
\hline & & LP(1)O1 & 1.87419 (1.86803) & $-0.26999(-0.25705)$ & $\sigma^{*}(\mathrm{C} 20-\mathrm{H} 24)$ & $0.01276(0.01209)$ & $0.70137(0.66118)$ & 0.2930 \\
\hline $\mathrm{O} 2 \cdots \mathrm{H} 25-\mathrm{C} 21$ & 2.556 & $\mathrm{LP}(2) \mathrm{O} 2$ & 1.97269 (1.86803) & $-0.65652(-0.25705)$ & $\sigma^{*}(\mathrm{C} 21-\mathrm{H} 25)$ & $0.01146(0.01137)$ & $0.70641(0.65909)$ & 0.209 \\
\hline O5 $\cdots$ H10-C9 & 2.324 & LP(1)O5 & $1.97273(1.97354)$ & $-0.66258(-0.65175)$ & $\sigma^{*}(\mathrm{C} 9-\mathrm{H} 10)$ & $0.01165(0.01184)$ & $0.69823(0.65601)$ & 0.628 \\
\hline \multirow[t]{2}{*}{ O6 $\cdots$ H23-C19 } & 2.278 & $\mathrm{LP}(1) \mathrm{O} 6$ & $1.97702(1.97845)$ & $-0.69553(-0.69126)$ & $\sigma^{*}(\mathrm{C} 19-\mathrm{H} 23)$ & $0.01490(0.01292)$ & $0.68884(0.64597)$ & 0.586 \\
\hline & & $\mathrm{LP}(2) \mathrm{O} 6$ & 1.87205 (1.86984) & $-0.27847(-0.27097)$ & $\sigma^{*}(\mathrm{C} 19-\mathrm{H} 23)$ & $0.01490(0.01292)$ & $0.68884(0.64597)$ & 2.721 \\
\hline \multirow[t]{2}{*}{ O6 $\cdots$ H23-C19 } & 2.278 & LP(1)O6 & $1.97712(1.97845)$ & $-0.69886(-0.69126)$ & $\sigma^{*}(\mathrm{C} 19-\mathrm{H} 23)$ & $0.01473(0.01292)$ & $0.68329(0.64597)$ & 0.586 \\
\hline & & $\mathrm{LP}(2) \mathrm{O} 6$ & $1.87194(1.86984)$ & $-0.28146(-0.27097)$ & $\sigma^{*}(\mathrm{C} 19-\mathrm{H} 23)$ & $0.01473(0.01292)$ & $0.68329(0.64597)$ & 2.680 \\
\hline
\end{tabular}


Table 4. Cont.

\begin{tabular}{|c|c|c|c|c|c|c|c|c|}
\hline Contact type A $\cdots$ H-D & A... D Dist. & (NBO) i & (Occupancy) i & $E_{\mathrm{i}}$ & (NBO) $j$ & (Occupancy) j & $E_{\mathrm{j}}$ & $E^{(2)}$ \\
\hline \multicolumn{9}{|c|}{ Complex 6} \\
\hline \multirow[t]{2}{*}{$\mathrm{C} 16 \cdots \mathrm{H} 4-\mathrm{C} 4$} & 2.669 & $\sigma(\mathrm{C} 4-\mathrm{H} 4)$ & $1.98252(1.98376)$ & $-0.53852(-0.53308)$ & $\pi^{*}(\mathrm{C} 16-\mathrm{C} 17)$ & $0.29616(0.30335)$ & $0.02878(0.01810)$ & 0.544 \\
\hline & & $\pi(\mathrm{C} 16-\mathrm{C} 17)$ & $1.66193(1.66922)$ & $-0.26125(-0.27086)$ & $\sigma^{*}(\mathrm{C} 4-\mathrm{H} 4)$ & $0.01050(0.01030)$ & $0.58775(0.58738)$ & 1.005 \\
\hline \multirow[t]{2}{*}{$\mathrm{O} 3 \cdots \mathrm{H} 8-\mathrm{C} 7$} & 2.360 & $\mathrm{LP}(1) \mathrm{O} 3$ & $1.97802(1.97901)$ & $-0.71166(-0.70195)$ & $\sigma^{*}(\mathrm{C} 7-\mathrm{H} 8)$ & $0.01316(0.01180)$ & $0.67217(0.64842)$ & 1.256 \\
\hline & & $\mathrm{LP}(2) \mathrm{O} 3$ & $1.87851(1.87585)$ & $-0.28994(-0.27736)$ & $\sigma^{*}(\mathrm{C} 7-\mathrm{H} 8)$ & $0.01316(0.01180)$ & $0.67217(0.64842)$ & 1.758 \\
\hline \multirow[t]{2}{*}{$\mathrm{O} 3 \cdots \mathrm{H} 8-\mathrm{C} 7$} & 2.360 & $\mathrm{LP}(1) \mathrm{O} 3$ & $1.97816(1.97901)$ & $-0.71673(-0.70195)$ & $\sigma^{*}(\mathrm{C} 7-\mathrm{H} 8)$ & $0.01316(0.01180)$ & $0.67815(0.64842)$ & 1.256 \\
\hline & & $\mathrm{LP}(2) \mathrm{O} 3$ & $1.87761(1.87585)$ & $-0.29446(-0.27736)$ & $\sigma^{*}(\mathrm{C} 7-\mathrm{H} 8)$ & $0.01316(0.01180)$ & $0.67815(0.64842)$ & 1.675 \\
\hline \multirow[t]{2}{*}{$\mathrm{O} 3 \cdots \mathrm{H} 6-\mathrm{C} 4$} & 2.503 & $\mathrm{LP}(1) \mathrm{O} 3$ & $1.97816(1.97901)$ & $-0.69908(-0.70195)$ & $\sigma^{*}(\mathrm{C} 4-\mathrm{H} 6)$ & $0.01029(0.00859)$ & $0.58979(0.57290)$ & 0.670 \\
\hline & & $\mathrm{LP}(2) \mathrm{O} 3$ & $1.87657(1.87585)$ & $-0.27608(-0.27736)$ & $\sigma^{*}(\mathrm{C} 4-\mathrm{H} 6)$ & $0.01029(0.00859)$ & $0.58979(0.5729)$ & 0.502 \\
\hline \multirow[t]{2}{*}{$\mathrm{O} 3 \cdots \mathrm{H} 5-\mathrm{C} 4$} & 2.478 & $\pi(\mathrm{C} 11-\mathrm{O} 3)$ & $1.97576(1.97564)$ & $-0.39637(-0.39003)$ & $\sigma^{*}(\mathrm{C} 4-\mathrm{H} 5)$ & $0.00951(0.0082)$ & $0.58267(0.56896)$ & 1.256 \\
\hline & & $\mathrm{LP}(1) \mathrm{O} 3$ & $1.97818(1.97901)$ & $-0.70613(-0.70195)$ & $\sigma^{*}(\mathrm{C} 4-\mathrm{H} 5)$ & $0.00951(0.0082)$ & $0.58267(0.56896)$ & 0.025 \\
\hline \multirow[t]{2}{*}{$\mathrm{O} 3 \cdots \mathrm{H} 5-\mathrm{C} 4$} & 2.478 & $\pi(\mathrm{C} 3-\mathrm{O} 3)$ & $1.97554(1.97564)$ & $-0.39514(-0.39003)$ & $\sigma^{*}(\mathrm{C} 4-\mathrm{H} 5)$ & $0.00972(0.0082)$ & $0.57705(0.56896)$ & 1.298 \\
\hline & & $\mathrm{LP}(1) \mathrm{O} 3$ & $1.97828(1.97901)$ & $-0.70568(-0.70195)$ & $\sigma^{*}(\mathrm{C} 4-\mathrm{H} 5)$ & $0.00972(0.00820)$ & $0.57705(0.56896)$ & 0.251 \\
\hline \multirow[t]{2}{*}{$\mathrm{O} 2 \cdots \mathrm{H} 14-\mathrm{C} 16$} & 2.278 & $\mathrm{LP}(1) \mathrm{O} 2$ & $1.97197(1.97301)$ & $-0.66209(-0.64902)$ & $\sigma^{*}(\mathrm{C} 16-\mathrm{H} 14)$ & $0.01430(0.01217)$ & $0.70710(0.67024)$ & 0.921 \\
\hline & & $\mathrm{LP}(2) \mathrm{O} 2$ & $1.85410(1.85107)$ & $-0.25874(-0.24082)$ & $\sigma^{*}(\mathrm{C} 16-\mathrm{H} 14)$ & $0.01430(0.01217)$ & $0.70710(0.67024)$ & 2.763 \\
\hline \multirow[t]{2}{*}{$\mathrm{O} 2 \cdots \mathrm{H} 13-\mathrm{C} 14$} & 2.346 & $\mathrm{LP}(1) \mathrm{O} 2$ & 1.97245 (1.97301) & $-0.65870(-0.64902)$ & $\sigma^{*}(\mathrm{C} 14-\mathrm{H} 13)$ & $0.01325(0.01153)$ & $0.70642(0.67422)$ & 0.322 \\
\hline & & $\mathrm{LP}(2) \mathrm{O} 2$ & $1.85944(1.85107)$ & $-0.25185(-0.24082)$ & $\sigma^{*}(\mathrm{C} 14-\mathrm{H} 13)$ & $0.01325(0.01153)$ & $0.70642(0.67422)$ & 2.010 \\
\hline \multirow[t]{2}{*}{$\mathrm{O} 1 \cdots \mathrm{H} 11-\mathrm{C} 10$} & 2.332 & $\pi(\mathrm{C} 1-\mathrm{O} 1)$ & 1.98826 (1.98947) & $-0.37137(-0.35014)$ & $\sigma^{*}(\mathrm{C} 10-\mathrm{H} 11)$ & $0.01643(0.01559)$ & $0.67607(0.65302)$ & 0.502 \\
\hline & & $\mathrm{LP}(1) \mathrm{O} 1$ & $1.96970(1.97111)$ & $-0.69047(-0.67364)$ & $\sigma^{*}(\mathrm{C} 10-\mathrm{H} 11)$ & $0.01643(0.01559)$ & $0.67607(0.65302)$ & 0.335 \\
\hline
\end{tabular}

Values in parentheses relate to the monomers (non-interacting units). 

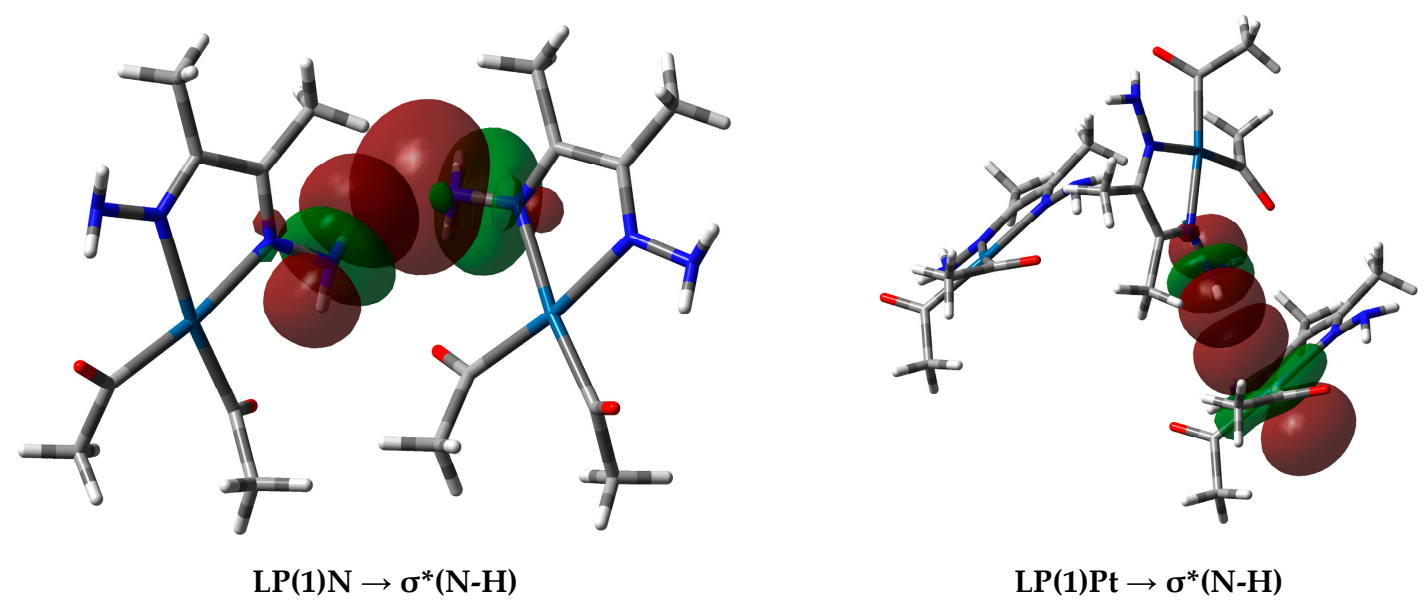

Figure 11. (Left) Interactions between the donor natural bond orbital (NBO) $(\mathrm{LP}(1) \mathrm{N})$ of the $\mathrm{N}$-atom and the acceptor $\mathrm{NBO}\left(\sigma^{*} \mathrm{~N}-\mathrm{H}\right)$ of the $\mathrm{N}-\mathrm{H} \cdots \mathrm{N}(2.273 \AA)$ interaction, and (right) donor NBO (LP(1)Pt) to the acceptor $\mathrm{NBO}\left(\sigma^{*} \mathrm{~N}-\mathrm{H}\right)$ for the $\mathrm{N}-\mathrm{H} \cdots \mathrm{Pt}(2.650 \AA)$ interaction in complex 3.

\section{Computational Details}

Hirshfeld surface analyses were carried out using Crystal explorer 3.1 [40]. Gaussian 03 [41] was used to create the wavefunction files containing the data needed for the atom in molecules (AIM) analyses. The Multiwfn program [42] was used to process the wavefunction files for topology analysis of complex clusters. In addition, natural population analyses were made using NBO 3.1 [43-49], which is built into Gaussian 03. The complex units and complex clusters were extracted from crystallographic information files (CIFs) obtained from the Cambridge Crystallographic Database Centre (CCDC Nos. 95819-95823 and 95825) [50]. All density functional theory calculations were performed using the B3LYP functional with 6-311G $(d, p)$ basis sets $[51,52]$ for nonmetal atoms and the LANL2DZ effective core potential [53-56] for Pt. The Cartesian coordinates of the clusters containing the intermolecular interactions identified from Hirshfeld analysis and used in the calculations are listed in the Supplementary Data.

\section{Conclusions}

In this work, Hirshfeld surface analysis of the crystal structures of six hydrazone-diacetyl platinum(II) complexes was conducted to determine and decompose the most important intermolecular interactions within the crystal lattices. In addition to the $\mathrm{H} \cdots \mathrm{H}$ contacts, $\mathrm{C}-\mathrm{H} \cdots \mathrm{O}$ interactions are common in all the crystals. Following the results obtained from the Hirshfeld analysis, the AIM and NBO methods were applied to describe the nature and strength of these interactions. At the bond critical points, positive values of $\nabla^{2} \rho(\mathrm{r})$ and electron density $(\rho(\mathrm{r}))$ values in the range $0.0031-0.0156 \mathrm{e} / \mathrm{a}_{0}{ }^{3}$ indicated closed-shell $\mathrm{H}$-bonding interactions. The highest $\rho(\mathrm{r})$ and, hence the highest covalent character, was observed for the O2 $\cdots \mathrm{H} 15-\mathrm{N} 3$ interaction in 1. Significant $\mathrm{Pt} \cdot \cdot \mathrm{H}$ interactions in 3 with $E^{(2)}$ values in the range 3.894-4.061 kJ/mol were detected using the NBO method. We found that the $\mathrm{d}_{\mathrm{xy}}, \mathrm{d}_{\mathrm{xz}}$, and s atomic orbitals are the main contributors to the Pt-NBO hybrid orbitals.

Supplementary Materials: Supplementary materials can be accessed at: http:/ /www.mdpi.com/1420-3049/21/ $12 / 1669 / \mathrm{s} 1$.

Acknowledgments: The authors would like to extend their sincere appreciation to the Deanship of Scientific Research at King Saud University for funding this research group NO (RGP-257-1435-1436).

Author Contributions: S.M.S. conceived and designed the work; A.B. and S.M.S. performed the calculations and wrote the paper.

Conflicts of Interest: The authors declare no conflict of interest. 


\section{References}

1. Desiraju, G.R.; Steiner, T. The Weak Hydrogen Bond in Structural Chemistry and Biology; Oxford University Press: Oxford, UK, 1999.

2. Bader, R.F.W. Atoms in Molecules: A Quantum Theory, 2nd ed.; Oxford University Press: Oxford, UK, 1994.

3. Bader, R.F.W. A bond path: A universal indicator of bonded interactions. J. Phys. Chem. A 1998, 102, 7314-7323. [CrossRef]

4. Parthasarathi, R.; Subramanian, V.; Sathyamurthy, N. Hydrogen bonding without borders: An atoms-in-molecules perspective. J. Phys. Chem. A 2006, 110, 3349-3351. [CrossRef] [PubMed]

5. Rosenberg, B.; Vancamp, L.; Trosko, J.E.; Mansour, V.H. Platinum compounds: A new class of potent antitumour agents. Nature 1969, 222, 385-386. [CrossRef] [PubMed]

6. O'Dwyer, P.J.; Stevenson, J.P.; Johnson, S.W. Cisplatin. Chemistry and Biochemistry of a Leading Anticancer Drug; Lippert, B., Ed.; Wiley-VCH: Weinheim, Germany, 1999; pp. 31-69.

7. Watson, M.; Barret, A.; Spence, R.; Twelves, C. Oncology, 2nd ed.; Oxford University Press: Oxford, UK, 2006.

8. Wheate, N.J.; Walker, S.; Craig, G.E.; Oun, R. The status of platinum anticancer drugs in the clinic and in clinical trials. Dalton Trans. 2010, 39, 8113-8127. [CrossRef] [PubMed]

9. Dhar, S.; Lippard, S.J. Bioinorganic Medicinal Chemistry; Alessio, E., Ed.; Wiley-VCH Verlag GmbH \& Co. KGaA: Weinheim, Germany, 2011; pp. 79-95.

10. Wang, X.; Guo, Z. Bioinorganic Medicinal Chemistry; Alonso, E., Ed.; Wiley-VCH: Weinheim, Germany, 2011; pp. 97-149.

11. Štarha, P.; Trávníček, Z.; Popa, A.; Popa, I.; Muchová, T.; Brabec, V. How to modify 7-azaindole to form cytotoxic $\mathrm{Pt}(\mathrm{II})$ complexes: Highly in vitro anticancer effective cisplatin derivatives involving halogen-substituted 7-azaindole. J. Inorg. Biochem. 2012, 115, 57-63. [CrossRef] [PubMed]

12. Ferri, N.; Cazzaniga, S.; Mazzarella, L.; Curigliano, G.; Lucchini, G.; Zerla, D.; Gandolfi, R.; Facchetti, G.; Pellizzoni, M.; Rimoldi, I. Cytotoxic effect of (1-methyl- $1 H$-imidazol-2-yl)-methanamine and its derivatives in PtII complexes on human carcinoma cell lines: A comparative study with cisplatin. Bioorg. Med. Chem. 2013, 21, 2379-2386. [CrossRef] [PubMed]

13. Icsel, C.; Yilmaz, V.T.; Ari, F.; Ulukaya, E.; Harrison, W.T.A. Trans-Dichloridopalladium(II) and platinum(II) complexes with 2-(hydroxymethyl)pyridine and 2-(2-hydroxyethyl)pyridine: Synthesis, structural characterization, DNA binding and in vitro cytotoxicity studies. Eur. J. Med. Chem. 2013, 60, 386-394. [CrossRef] [PubMed]

14. Spackman, M.A.; McKinnon, J.J. Fingerprinting intermolecular interactions in molecular crystals. CrystEngComm 2002, 4, 378-392. [CrossRef]

15. McKinnon, J.J.; Jayatilaka, D.; Spackman, M.A. Towards quantitative analysis of intermolecular interactions with Hirshfeld surfaces. Chem. Commun. 2007, 3814-3816. [CrossRef]

16. Spackman, M.A.; McKinnon, J.J.; Jayatilaka, D. Electrostatic potentials mapped on Hirshfeld surfaces provide direct insight into intermolecular interactions in crystals. CrystEngComm 2008, 10, 377-388. [CrossRef]

17. Spackman, M.A.; Jayatilaka, D. Hirshfeld surface analysis. CrystEngComm 2009, 11, 19-32. [CrossRef]

18. Hirshfeld, F.L. Bonded-atom fragments for describing molecular charge densities. Theor. Chim. Acta 1977, 44, 129-133. [CrossRef]

19. Martin, A.D.; Hartlieb, K.J.; Sobolev, A.N.; Raston, C.L. Hirshfeld surface analysis of substituted phenols. Cryst. Growth Des. 2010, 10, 5302-5306. [CrossRef]

20. Chattopadhyay, B.; Mukherjee, A.K.; Narendra, N.; Hemantha, H.P.; Sureshbabu, V.V.; Helliwell, M.; Mukherjee, M. Supramolecular architectures in 5,5'-substituted hydantoins: Crystal structures and Hirshfeld surface analyses. Cryst. Growth Des. 2010, 10, 4476-4484. [CrossRef]

21. Seth, S.K.; Sarkar, D.; Kar, T. Use of $\pi-\pi$ forces to steer the assembly of chromone derivatives into hydrogen-bonded supramolecular layers: Crystal structures and Hirshfeld surface analyses. CrystEngComm 2011, 13, 4528-4535. [CrossRef]

22. Seth, S.K.; Saha, I.; Estarellas, C.; Frontera, A.; Kar, T.; Mukhopadhyay, S. Supramolecular self-assembly of M-IDA complexes involving lone-pair $\cdots \pi$ interactions: Crystal structures, Hirshfeld surface analysis, and DFT calculations $\left[\mathrm{H}_{2} \mathrm{IDA}=\right.$ iminodiacetic acid, $\left.\mathrm{M}=\mathrm{Cu}(\mathrm{II}), \mathrm{Ni}(\mathrm{II})\right]$. Cryst. Growth Des. 2011, 11, 3250-3265. [CrossRef] 
23. McKi, J.J.; Spackman, M.A.; Mitchell, A.S. Novel tools for visualizing and exploring intermolecular interactions in molecular crystals. Acta Crystallogr. B 2004, 60, 627-668.

24. Rohl, A.L.; Moret, M.; Kaminsky, W.; Claborn, K.; Mckinnon, J.J.; Kahr, B. Hirshfeld surfaces identify inadequacies in computations of intermolecular interactions in crystals: Pentamorphic 1,8-dihydroxyanthraquinone. Cryst. Growth Des. 2008, 8, 4517-4525. [CrossRef]

25. Parkin, A.; Barr, G.; Dong, W.; Gilmore, C.J.; Jayatilaka, D.; Mckinnon, J.J.; Spackman, M.A.; Wilson, C.C. Comparing entire crystal structures: Structural genetic fingerprinting. CrystEngComm 2007, 9, 648-652. [CrossRef]

26. Fabbiani, F.P.A.; Byrne, L.T.; Mckinnon, J.J.; Spackman, M.A. Solvent inclusion in the structural voids of form II carbamazepine: Single-crystal X-ray diffraction, NMR spectroscopy, and Hirshfeld surface analysis. CrystEngComm 2007, 9, 728-731. [CrossRef]

27. Spackman, M.A.; Byrom, P.G. A novel definition of a molecule in a crystal. Chem. Phys. Lett. 1997, 267, 215-220. [CrossRef]

28. McKinnon, J.J.; Mitchell, A.S.; Spackman, M.A. Hirshfeld surfaces: A new tool for visualising and exploring molecular crystals. Chem. Eur. J. 1998, 4, 2136-2141. [CrossRef]

29. Bernstein, J.; Davis, R.E.; Shimoni, L.; Chang, N.L. Patterns in hydrogen bonding: Functionality and graph set analysis in crystals. Angew. Chem. Int. Ed. 1995, 34, 1555-1573. [CrossRef]

30. Grabowsky, S.; Dean, P.M.; Skelton, B.W.; Sobolev, A.N.; Spackman, M.A.; White, A.H. Crystal packing in the 2-R,4-oxo-[1,3- $a / b]$-naphthodioxanes-Hirshfeld surface analysis and melting point correlation. CrystEngComm 2012, 14, 1083-1093. [CrossRef]

31. Carrol, M.T.; Chang, C.; Bader, R.F.W. Prediction of the structures of hydrogen-bonded complexes using the Laplacian of the charge density. Mol. Phys. 1988, 63, 387-405. [CrossRef]

32. Carroll, M.T.; Chang, C.; Bader, R.F.W. An analysis of the hydrogen bond in BASE-HF complexes using the theory of atoms in molecules. Mol. Phys. 1998, 65, 695-722. [CrossRef]

33. Koch, U.; Popelier, P. Characterization of $\mathrm{C}-\mathrm{H} \cdots \mathrm{O}$ hydrogen bonds on the basis of the charge density. J. Chem. Phys. 1995, 99, 9747-9754. [CrossRef]

34. Espinosa, E.; Molins, D.E.; Lecomte, C. Hydrogen bond strengths revealed by topological analyses of experimentally observed electron densities. Chem. Phys. Lett. 1998, 285, 170-173. [CrossRef]

35. Bader, R.F.W.; Essen, H. The characterization of atomic interactions. J. Chem. Phys. 1984, 80, $1943-1960$. [CrossRef]

36. Popelier, P.L.A. Atoms in Molecules: An Introduction; Pearson Education Limited: Harlow, UK, 2000.

37. Parthasarathi, R.; Subramanian, V.; Sathyamurthy, N. Hydrogen bonding in phenol, water, and phenol-water clusters. J. Phys. Chem. A 2005, 109, 843-850. [CrossRef] [PubMed]

38. Rozas, I.; Alkorta, I.; Elguero, J. Behavior of ylides containing N, O, and C atoms as hydrogen bond acceptors. J. Am. Chem. Soc. 2000, 122, 11154-11161. [CrossRef]

39. Espinosa, E.; Alkorta, I.; Elguero, J.; Molins, E. From weak to strong interactions: A comprehensive analysis of the topological and energetic properties of the electron density distribution involving $\mathrm{X}-\mathrm{H} \cdots \mathrm{F}-\mathrm{Y}$ system. J. Chem. Phys. 2002, 117, 5529-5542. [CrossRef]

40. Wolff, S.K.; Grimwood, D.J.; McKinnon, J.J.; Turner, M.J.; Jayatilaka, D.; Spackman, M.A. Crystal Explorer, version 3.1; University of Western Australia: Crawley, Australia, 2012.

41. Frisch, M.J.; Trucks, G.W.; Schlegel, H.B.; Scuseria, G.E.; Robb, M.A.; Cheeseman, J.R.; Montgomery, J.A.; Vreven, J.T.; Kudin, K.N.; Burant, J.C.; et al. Gaussian 03; revision C01; Gaussian Inc.: Wallingford, CT, USA, 2004.

42. Lu, T.; Chen, F. Multiwfn: A multifunctional wavefunction analyzer. J. Comput. Chem. 2012, 33, 580-592. [CrossRef] [PubMed]

43. Carpenter, J.E.; Weinhold, F. Analysis of the geometry of the hydroxymethyl radical by the different hybrids for different spins natural bond orbital procedure. J. Mol. Struct. (Theochem) 1988, 169, 41-62. [CrossRef]

44. Foster, J.P.; Weinhold, F. Natural hybrid orbitals. J. Am. Chem. Soc. 1980, 102, 7211-7218. [CrossRef]

45. Reed, A.E.; Weinhold, F. Natural bond orbital analysis of near-Hartree-Fock water dimer. J. Chem. Phys. 1983, 78, 4066-4073. [CrossRef]

46. Reed, A.E.; Weinhold, F. Natural localized molecular orbitals. J. Chem. Phys. 1983, 83, 1736-1740. [CrossRef]

47. Reed, A.E.; Weinstock, R.B.; Weinhold, F. Natural population analysis. J. Chem. Phys. 1985, 83, 735-746. [CrossRef] 
48. Reed, A.E.; Curtiss, L.A.; Weinhold, F. Intermolecular interactions from a natural bond orbital, donor-acceptor viewpoint. Chem. Rev. 1988, 88, 899-926. [CrossRef]

49. Weinhold, F.; Carpenter, J.E. The natural bond orbital Lewis structure concept for molecules, radicals, and radical ions. In The Structure of Small Molecules and Ions; Naaman, R., Vager, Z., Eds.; Plenum: New York, NY, USA, 1988; pp. 227-236.

50. Kluge, T.; Bette, E.; Bette, M.; Schmidt, J.; Steinborn, D. Hydrazone-diacetyl platinum(II) complexes: Substituent effect on intramolecular N-H . O hydrogen-bond strength. J. Organomet. Chem. 2014, 762, 48-57. [CrossRef]

51. McLean, A.D.; Chandler, G.S. Contracted Gaussian basis sets for molecular calculations. I. 2nd-row atoms, $Z=11-18$. J. Chem. Phys. 1980, 72, 5639-5648. [CrossRef]

52. Raghavachari, K.; Binkley, J.S.; Seeger, R.; Pople, J.A. Self-consistent molecular orbital methods. XX. Basis set for correlated wavefunctions. J. Chem. Phys. 1980, 72, 650-654.

53. Dunning, T.H., Jr.; Hay, P.J. Modern Theoretical Chemistry; Schaefer, H.F., Ed.; Plenum: New York, NY, USA, 1977; Volume 3, pp. 1-28.

54. Hay, P.J.; Wadt, W.R. Ab initio effective core potentials for molecular calculations-Potentials for the transition-metal atoms Sc to Hg. J. Chem. Phys. 1985, 82, 270-283. [CrossRef]

55. Wadt, W.R.; Hay, P.J. Ab initio effective core potentials for molecular calculations-Potentials for main group elements Na to Bi. J. Chem. Phys. 1985, 82, 284-298. [CrossRef]

56. Hay, P.J.; Wadt, W.R. Ab initio effective core potentials for molecular-Potentials for K to Au including the outermost core orbitals. J. Chem. Phys. 1985, 82, 299-310. [CrossRef]

Sample Availability: Not available.

(C) 2016 by the authors; licensee MDPI, Basel, Switzerland. This article is an open access article distributed under the terms and conditions of the Creative Commons Attribution (CC-BY) license (http:/ / creativecommons.org/licenses/by/4.0/). 